\title{
artículos
}

\section{La "Sforzinda" de Filarete: Ciudad ideal y recreación del mundo}

Berthold Hub

ETH Zurich

RESUMEN

El "Libro architettonico", el cual fue redactado por Filarete alrededor del año 1460 , se ha considerado siempre como un mero tratado de arquitectura. No obstante, existe en él más de una línea directriz: la primera trata de destacar los elementos racionales y funcionales de la arquitectura, y la segunda pone de relieve lo simbólico, lo mágico, así como toda una serie de referencias al micro y macrocosmos, la astrología y la alquimia. En estos pasajes del libro el arquitecto del Renacimiento se describe a sí mismo como "alter deus", el cual considera su obra como recreación o bien como restablecimiento de una creación que inicialmente era buena, pero que entretanto ha sido corrompida.

PALABRAS CLAVE: Tratados Arquitectura/ Iconología/ Renacimiento.

Filarete's "Sforzinda". Ideal City and World Recreation.

ABSTRACT

The "Libro architettonico", which Filarete wrote ca. 1460, has previously always been treated in the history of art as if it were merely a tractate on architecture. But in addition to the thread in the text that pursues the rationality and functionality of architecture, there is a second thread that is symbolic and magical in nature, full of micro-macrocosmic, astrological, and alchemical references. In these passages, the Renaissance architect characterizes himself as "alter deus", who sees his work as a new creation or restoration of the originally good Creation, which has in the meantime become corrupted.

KEY WORDS: Architecture Treatise/ Iconology/ Renaissance.

Antonio di Piero Averlino, llamado Filarete, maestro de las puertas de bronce de la iglesia de San Pedro en Roma, así como arquitecto del Castello Sforzesco y del Ospedale Maggiore en Milán, relata en su tratado, el cual él mismo llama "Libro architettonico", redactado posiblemente entre 1461 y 1464, en forma de diálogo con el duque milanés Francesco Sforza y su hijo Galeazzo Maria Sforza, la concepción y construcción ideales de una ciudad que lleva el nombre de su constructor: "Sforzinda"1.

* HUB, Berthold.: "La 'Sforzinda' de Filarete: Ciudad ideal y recreación del mundo", en Boletín de Arte, n²9, Departamento de Historia del Arte, Universidad de Málaga, 2008, págs. 11-36.

1 Sobre la datación SPENCER, J. R.: "La Datazione del Trattato del Filarete desunta del suo esame interno", Rivista d'Arte $\mathrm{n}^{\circ}$ 31, Florencia, 1956, págs. 93-103. Sobre la tradición del manuscrito cfr. TIGLER, P.: Die Architekturtheorie des Filarete. Berlín, de Gruyter, 1963, pág. 8 y ss.; FINOLI, A. M. y GRASSI, L. (eds.): 


2: articulos Berthold Hub

La Historia del Arte siempre ha considerado la obra de Filarete como si fuera un mero tratado de arquitectura. Pero aparte de la línea dedicada a la racionalidad y funcionalidad de la arquitectura, también nos vemos confrontados con otra linea de naturaleza simbólica y mágica, plena de referencias astrológicas y alquimistas, y marcada de una imaginación utópica. La literatura sobre Filarete se ha dedicado casi por completo a tratar el primer aspecto, marginando al segundo y calificándolo como divagación literaria fantástica o romántica sin relevancia para el conjunto ${ }^{2}$. Como consecuencia, se suele asumir que el plano como base de la estructura de Sforzinda, es sólo una aplicación o una expresión del nuevo diseño exacto del Renacimiento, que debe presentar la arquitectura como una ciencia, quitandole el estatus de las artes machinicae, elevándola al estado de una ars liberalis. Las siguientes exposiciones tratan de demostrar que Filarete no sólo tenía la intención de concebir un plano urbanístico construído en base a la matemática y fácil de poner en práctica, sino que quería poner de relieve el significado a transmitir a través del diseño urbanístico.

En cuánto a la forma de la ciudad Filarete comenta sólamente que ésta consiste de "dos cuadrados, uno superpuesto al otro, no encontrándose los ángulos juntos, sino cada uno equidistante entre los otros dos"3. Los dos códices principales de su tratado cuentan con tres planos de Sforzinda. El primero, siendo menor, se encuentra encerrado en un círculo y colocado en un paisaje sin tomar en consideración la perspectiva [1]. Más adelante en el tratado aparece el segundo diseño, con una representación mucho más clara y de mayor proporción. Esta vez la ciudad se encuentra dentro de una doble circunferencia [2]. El tercer plano ya es más cercano a un verdadero trazado [3]. Los elementos básicos de ambos cuadrados están finamente delineados, mientras que el contorno de la estrella de ocho puntas, al igual que el círculo exterior, han sido resaltados visiblemente. Según el texto, la muralla de

\footnotetext{
Antonio Averlino (detto I/ Filarete): Trattato di architettura. Milano, II Polifilo, 1972, (PEDRAZA, P. [trad.], Vitoria-Gasteiz, Ephialte, 1990) vol. 1, pág. CVIII y ss. El tratado de Filarete se mantuvo inédito hasta el siglo XIX, sin embargo tuvo bastante influencia a través de varias transcripciones y traducciones latinas (p. e. para el rey de Hungría Matías Corvinus por medio de su historiógrafo Antonio Boffini d'Ascoli, al diseñar una ciudad ideal junto al Danubio con un edificio universitario, obedeciendo las descripciones de Filarete y orientándose en la "Casa de la virtud y del vicio"; cfr. SCAFI, A.: "La città ideale del Filarete e il Rinascimento ungharese", II Veltro. Rivista della civiltà italiana $n^{\circ} 37$, Roma, 1993, págs. 11-26, SCAFI, A.: "Filarete e l'Ungheria. L'utopia universitaria di Mattio Corvino", Storia dell'Arte n 81, Florencia, 1994, págs. 137-168. El original se considera como desaparecido; el manuscrito más importante preservado hasta el día de hoy es el Codex Magliabechianus de la Biblioteca Nazionale Centrale de Florencia que está disponible en tres ediciones modernas: SPENCER, J. R. (ed. y trans.): Filarete's Treatise on Architecture. Being the Treatise by Antonio di Piero Averlino, known as Filarete. 2 vols., New Haven, Yale University Press, 1965; FINOLI, A. M. y GRASSI, L. (eds.): op. cit.

2 Excluyendo los trabajos de SINISI, S.: Filarete nascosto. Salerno, Istituto Universitario di Magistero, 1971, SINISI, S.: "Il Palazzo della Memoria", Arte Lombarda n 38, Milano, 1973, págs. 150-160); LANG, S.: "The Ideal City. From Plato to Howard", The Architectural Review n 112, Londres, 1952, pág. 95 y ss., y LANG, S.: "Sforzinda, Filarete and Filelfo", Journal of the Warburg and Courtauld Institutes n ${ }^{\circ}$ 35, Londres, 1972, págs. 391-397, a quienes debemos el enfoque especial de este ensayo. También cabe mencionar a BAUER, $\mathrm{H}$.: Kunst und Utopie. Studien über das Kunst- und Staatsdenken in der Renaissance. Berlín, de Gruyter, 1965 , pág. 70 y ss.

3 Antonio Averlino... op. cit., Libro II, fol. 13r, pág. 67.
} 


\section{Q: artículos La "Sforzinda" de Filarete...}
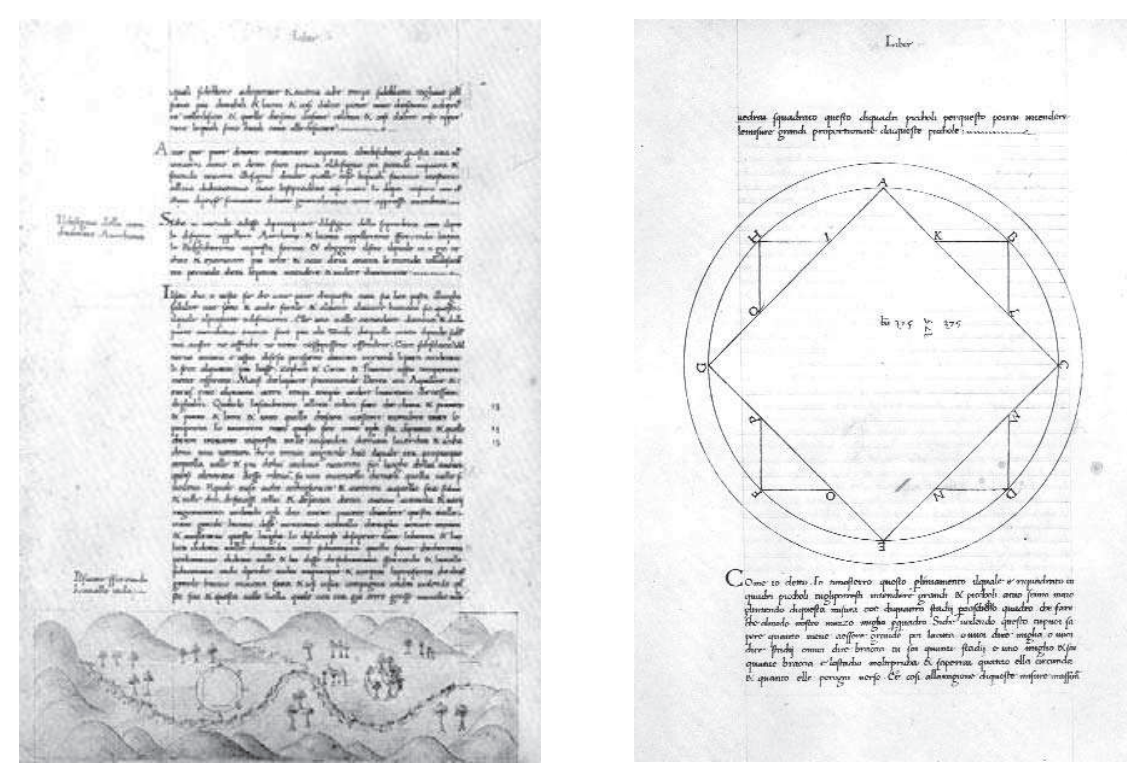

1. ANTONIO AVERLINo "FILARETE": Tratado de arquitectura, c. 1460. Biblioteca Nazionale Centrale di Firenze, Magliabechianus II,IV,140, fol. 11 .

2. Antonio AVERLINO "FILARETE: Tratado de arquitectura, c. 1460. Biblioteca Nazionale Centrale di Firenze, Magliabechianus II,IV,140, fol. $13 v$.

la ciudad deberá construirse siguiendo el contorno de la estrella de ocho puntas, mientras que el círculo alrededor servirá de trinchera. Las cuatro calles principales nacen en los pórticos de la ciudad, justo en los puntos de intersección de los cuadrados. Los ocho canales y ochos calles principales parten de las puertas de la ciudad, de los puntos de cruce de los rectángulos y de las puntas de las torres angulares y conectan así con el centro ciudad y sus plazas. A medio trecho, las calles y los canales son atravesados por una calle anular. En cada punto de intersección se encuentra una plaza con la función de sede comercial y de la vída pública de cada barrio. La ciudad se elevará conforme uno vaya penetrando hacia el centro, donde se instalará una reserva de agua suministrada por un acueducto y previsto para garantizar el abastecimiento de agua de la población, así como la navegabilidad de los canales y la limpieza de las calles a través de inundaciones al desbordar los canales, en el caso dado. En un principio, sin embargo, Filarete había planeado distinguir el centro mediante una torre alta, a la cual volveremos más adelante ${ }^{4}$.

4 Ibídem., Libro II, fol. 14r, pág. 68. 


\section{Q: artículos Berthold Hub}

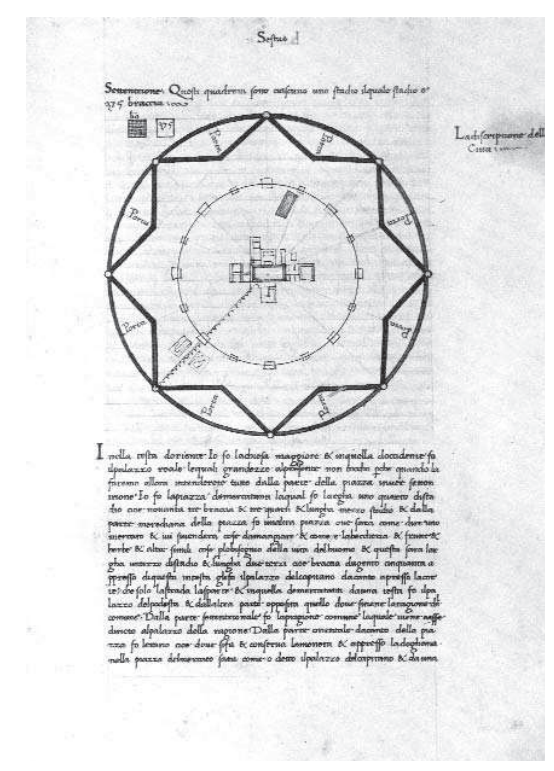

3. ANTONIO AVERLINO "FILARETE": Tratado de arquitectura, c. 1460. Biblioteca Nazionale Centrale di Firenze, Magliabechianus II,IV,140, fol. $43 r$.
En primer lugar, tendríamos que tratar por extenso de la función metafísica de la geometría en general, a la que aparte de su utilidad práctica también se le atribuyó siempre la función de reflejar lo divino y acercarlo al hombre, así como de la importancia de las figuras geométricas del círculo y del cuadrado en particular. El círculo y la esfera así como todas las figuras cuaternarias como el cubo, el cuadrado o la cruz y el número cuatro, son constantes históricas tanto en las tradiciones occidentales como en las orientales y representan abstracciones de la estructura esencial del cosmos y cifras del órden de la creación 5 . El círculo o la esfera como las figuras geométricas más cercanas a la perfección, donde no existe ni un arriba ni un abajo, ni un inicio ni un fin, y todos los puntos de la periferia tienen la misma distancia desde el núcleo, eran considerados como representación del conjunto del cosmos divino o del cielo (ciclo solar) en contraposición al mundo material de acá, que suele ser representado por la imagen del último período cenozoico. La disposición espacial del mundo se refleja en los cuatro puntos cardinales, la organización temporal en las cuatro estaciones del año y el ordenamiento material en los cuatro elementos. De aquí surge una sistemática cuarternaria, que se ha desarrollado con más profundidad a lo largo de la Edad Media cristiana. Esto significa que aquél que buscaba la cuadratura del círculo, intentaba al mismo tiempo traducir la perfección, la eternidad y la unidad divina en lo espacial, lo temporal y lo material, y de hacer lo supernatural operante en este mundo. Por otro lado, la rotación del cuadrado (p.e. la cúpula sobre la intersección de la nave) busca un traspase de la cuadratura material, una deificación de la dimensión huma-

5 BRONDER, B.: "Das Bild der Schöpfung und der Neuschöpfung der Welt als orbis quadratus", Frühmittelalterliche Studien $n^{\circ}$ 6, Berlín, 1972, págs. 188-210; REUDENBACH, B.: "In mensuram humani corporis. Zur Herkunft der Auslegung und Illustration von Vitruv III,1 n. 15. und 16. Jahrhundert", en MEIER, C. y RUBERG, U. (eds.): Text und Bild. Aspekte des Zusammenwirkens zweier Künste in Mittelalter und früher Neuzeit. Wiesbaden, Reichert, 1980, págs. 651-688; LURKER, M.: Der Kreis als Symbol im Denken, Glauben und künstlerischen Gestalten der Menschheit. Tübingen, Wunderlich, 1981; FINCKH, R.: Minor Mundus Homo. Studien zur Mikrokosmos-Idee in der mittelalterlichen Architektur. Göttingen, Vandenhoeck \& Ruprecht, 1999, pág. 88 y ss. 
na, y con ello alcanzar una reconciliación y unificación de la dimensión humana con la divina. El hombre ha utilizado constantemente el círculo y el cuadrado como símbolos de la estructura esencial del cosmos en la arquitectura, tanto en edificaciones como en planos urbanísticos, para participar en un orden y una armonía mayor6.

Filarete se une a esta tradición en primer lugar legitimando y explicando la arquitectura antropomorfológicamente, siguiendo los pasos de Vitruvio 7 . Ya en el proemio del libro que precede al tratado en sí, Filarete anuncia su voluntad de querer demostrar que todas las formas de construcción arquitectónica, sea que se trate sólo de un edificio o de una ciudad entera, "todas derivan de la figura y forma del hombre"8. Vitruvio había supuesto que las proporciones numéricas y las armonías del cosmos también se reflejaban en el hombre, cuyas leyes tomó como base para el arte de construcción ${ }^{9}$. Aparte de los diferentes tipos de edificaciones, de la columnación y del sistema modular, como resultado de la proporción de las partes del cuerpo entre ellas mismas en general, y de las medidas de la cabeza en particular, resaltan el círculo y el cuadrado que se derivan de la relación entre ser humano con el $\operatorname{cosmos}^{10}$. Ya que el cuerpo humano proporcionalmente bien distribuido y con los miembros exteriorizados, puede ser inscrito en un círculo o un cuadrado, Filarete utiliza ambas figuras como base para el conjunto de la geometría de la construcción. El hombre siendo la creación perfecta de Dios y representando su viva imagen, tiene la facultad de transmitir la idea divina omnipresente, y ésta tiene que seguir el hombre creador. De esta manera, el hombre puede tomar parte en la creación de Dios a través de la construcción: "Pues quiso Dios que el hombre, hecho a su imagen y semejanza, participase en ser capaz de hacer algo a su semejanza mediante el intelecto que le concedió"11.

6 MÜLLER, W.: Die Heilige Stadt. Roma quadrata, Himmlisches Jerusalem und die Mythe vom Weltnabel. Stuttgart, Kohlhammer, 1961; WU, Nelson I.: Chinese and Indian Architecture. The City of Man, the Mountain of God, and the Realm of the Immortals. Londres, Prentice-Hall, 1963; BRENTJES, B.: Die Stadt des Yima. Weltbilder in der Architektur. Leipzig, Seemann, 1981; JOHNSTON, N. J.: Cities in the Round. Seattle, University of Washington Press, 1983; MANN, A.: Ringwälle, Atlantis und Utopien. Kreisförmige und andere zentrierte Siedlungs- oder Stadtstrukturen in den gesellschaftlichen Umbrüchen von der Urgeschichte über Platon zur Neuzeit (tesis doctoral), Technische Hochschule Aachen, 1983. En este contexto cabe mencionar la comparación del mundo (cosmos) con la ciudad, así como la visión de la imagen de Dios como arquitecto de su creación. Como señalado por CHOJECKA, E.: "Die Kunsttheorie der Renaissance und das wissenschaftliche Werk des Kopernikus", Zeitschrift für Kunstgeschichte n 35, Munich, 1972, págs. 257-281, las categorías estéticas y ante todo arquitectónicas, obtenidas a través de visiones cosmológicas, repercutieron nuevamente en la imagen del cosmos.

7 Sobre todo en los Libros I, II y VII.

8 Antonio Averlino..., Dedicación, fol. 1v, 4, pág. 49

9 Vitruvius: De architectura libri decem III,1. Cfr. REUDENBACH, B.: op. cit.

10 Antonio Averlino..., Libro I, fol. 3v-4r, pág. 52. La figura vitruviana del homo ad quadratum et ad circulum tan influyente para los teóricos de la arquitectura posteriores a Filarete. Cfr. también REUDENBACH, B.: op. cit.; WITTKOWER, R.: Architectural Principles in the Age of Humanism. 5 ed., Londres, Academy Ed., 1998, pág. 16 y ss.; KURDZIALEK, M.: "Der Mensch als Abbild des Kosmos", en ZIMMERMANN, A. (ed.): Der Begriff der Representatio im Mittelalter. Stellvertretung, Symbol, Zeichen, Bild. Berlín, de Gruyter, 1971, págs. 35-75; BARKAN, L.: Nature's Work of Art. The Human Body as Image of the World. New Haven, Yale University Press, 1975, pág. 134 y ss.; ZÖLLNER, F.: Vitruvs Proportionsfigur. Quellenkritische Studien zur Kunstliteratur im 15. und 16. Jahrhundert. Worms, Werner, 1987.

11 Antonio Averlino..., Libro I, 5r, pág. 54 y ss. 


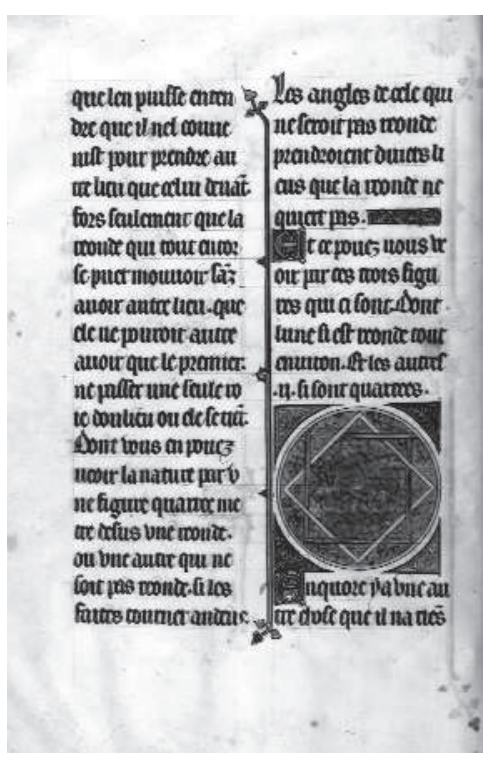

4. GoSSOUIN DE METZ: Image du Monde, ca. 1250. Bibliothèque National de France, Paris, MS fonds francais 574, $F^{\circ} 44 d$, fig. 8 .
Una figura idéntica a la de Filarete, es decir una figura que consiste en dos cuadrados superpuestos y circunvalados, la encontramos en tratados astronómicos del siglo XIII en adelante, por ejemplo en el Liber de Sphaera de Juan de Sacrobosco (el material didáctico más utilizado durante el siglo XIV y XV) ${ }^{12}$; en la Image du Monde de Gossouin de Metz [4] ${ }^{13}$ o en el De Astrologia de Ludovicus de Angulo [5] ${ }^{14}$.

Un esquema de este tipo deriva de la configuración diagramática de los cuatro elementos básicos y las cuatro cualidades básicas. Esto es más claro en ilustraciones posteriores, como en el comentario de Christophorus Clavius sobre la Shaera de Sacrobosco, impreso por primera vez en 1570 [6] ${ }^{15}$. Las cuatro cualidades básicas están dispuestas en un cuadrado, las cualidades contrarias se encuentran opuestas diagonalmente: caliente opuesto al frío $y$ seco opuesto al húmedo. Los cuatro elementos, que participan en estas cuali-

\footnotetext{
12 Juan de Sacrobosco, probablemente de procedencia inglesa (de acuerdo a su posible ciudad natal Hollywood, luego también conocida bajo el nombre de Halifax/Yorkshire); fue redactado $1220 \mathrm{ca}$. en calidad de libro didáctico de enseñanza universitaria; fue materia obligatoria en la mayor parte de las universidades hasta el siglo XVII; tuvo una distribución excepcional a causa de traducciones en lenguas nacionales, así como debido a numerosos comentarios, entre los cuales destacan los de Cecco d'Ascoli, Prosdocimo de Beldomandis y de John de Fundis; cfr. THORNDIKE, L.: The Sphere of Sacrobosco and Its Commentators. Chicago, University of Chicago Press, 1949 (pág. 118 y ss., el texto de Sacrobosco acerca de nuestra figura); cfr. BRÉVART, F. B. (ed.): Johannes von Sacrobosco, Das Puechlein von der Spera. Abbildung der gesamten Überlieferung, kritische Edition, Glossar. Göppingen, Kümmerle, 1979. El inventario de la Biblioteca de Francesco Sforza del año 1459 enumera varias ediciones de la Sphaera de Sacrobosco; cfr. PELLEGRIN, E.: La Bibliothèque des Visconti et des Sforza ducs de Milan, au Xve siecle. Paris, Librairie F. de Nobele, 1955, n. B. 88 (A. 409) y B. 104; cfr. A. 290. La misma figura se describe también en los libros de enseñanza de Grosseteste (GROSSETESTE, R. : "De Sphaera", en BAUR, L. (ed.): Die philosophischen Werke des Robert Grosseteste, Bischof von Lincoln. Münster, Aschendorff, 1912, pág. 10 y ss., (ca. medio siglo después; MACLAREN, B. R.: A Critical Edition and Translation, with Commentary, of John Pecham's Tractatus de Sphaera. Tésis doctoral, Universidad de Wisconsin-Madison, 1978, pág. 154 y ss.), que competían con el tratado de Sacrobosco, pero que no pudieron imponerse debido al gran conocimiento y a la amplia divulgación del texto de Sacrobosco.

13 PRIOR, Oliver H. (ed.): L'Image du Mond de Maître Gossouin. Loussanne, Impr. Réunies, 1913, pág. 99 y ss. El texto reproducido es aquél de Ms fonds francais 574 de la Biblioteca Nacional de Paris. En la Biblioteca de Francesco Sforza había varias ediciones de la Image du Monde; cfr. PELLEGRIN, Elisabeth: op. cit., n. B. 790 (A. 411); cfr. n. A. 829.

14 Biblioteca del Cantón de San Gallo, Vad. Slg. Ms. 427, fol. 7v (una copia de este manuscrito se encuen-
} 


2: artículos La "Sforzinda" de Filarete...

dades, forman otra tetrada y también pueden ser alineados como dos pares de cualidades opuestos: fuego - agua y aire - tierra. El resultado es un sistema estable, ya que la fuerza exterior que interfiere es contrarrestada por la fuerza cohesiva del compartir, que es emblematizado por el círculo. Esta disposición ordenada de un todo unificado es el diagrama conceptual del universo que ha sido atribuido al mismo Pitágoras. También lo encontramos glosado en el Timeo de Platón, ha sido sustentado por Aristóteles ${ }^{16}$, repetido por toda autoridad medieval importante y aceptado

tra en la Biblioteca de Warburg, Londres). Exclusivamente S. Lang se ha referido a esto (LANG, Susi: "The Ideal City. From Plato to Howard", The Architectural Review n 112, Londres, 1952, pág. 95 y ss.; Eadem: "Sforzinda, Filarete and Filelfo", Journal of the Warburg and Courtauld Institutes n 35, Londres, 1972, pág. 391 y ss.). Este esquema reproducido en tratados astrológicos también es ampliamente conocido en otros ámbitos. Lo vemos por ejemplo en el cuadro dedicatorio del Dioscórides de Viena como marco de un retrato de la Princesa Bizantina Anicia Juliana (Viena, Biblioteca Nacional, Cod. Med. gr. i, fol. 6v; ca. 500 d. C.; KATZENELLENBOGEN, Adolf: Allegories of the Virtues and Vices in Mediaeval Art. From the Early Christian Times to the Thirteenth Century. Toronto, University of Toronto Press, 1989, fig. 29). En la denominada capa roja de coronación de Enrique II la figura constituye el borde el cual cerca los diferentes signos zodiacos (ca. en 1000 a.C., hoy en el Museo Diocesano de Bamberg; O'CONNOR, Elizabeth C.W.: The Star Mantle of Henry II. Tésis doctoral, Columbia University, 1980). Hay numerosos ejemplos preservados del arte árabe y mozárabe de la Península Ibérica, p.e. en el Pendón de Las Navas de Tolosa (Monasterio de las Huelgas Reales), rodeado de versos del Corán, que alaban la grandeza del emperador del mundo Allah (YARZA, Joaquín: Arte y Architectura en España 500-1250. Madrid, Ediciones Cátedra, 1997, pág. 246); en numerosas construcciones de cúpula, p.e. en la Bóveda del Mihrab de la Mezquita de Córdoba, en las cúpulas de la Mezquita de Toledo, hoy cononcida bajo el nombre de Cristo de la Luz, o de la iglesia de Torres del Río. De aquí la figura parece haberse impuesto en construcciones de cúpulas barrocas de Turín por Guarino Guarini (cfr. DE BERNARDI FERRERO, Daria: I 'Disegni d'Architettura civile et ecclesiastica' di Guarino Guarini e l'arte del Maestro. Turín, Albra, 1966, pág. 24 y ss., o MEEK, Harold Alan: Guarino Guarini and his Architecture. New Haven, Yale University Press, 1988, pág. 45 y ss.). Es muy probable que también conocía la ilustración del esquema en la Architectura Civil recta y obliqua de Juan Caramuel (Vigeven, 1678, pl. XXIX; BATTISTI, Eugenio: "Schemata nel Guarini", en Guarino Guarini e l'internazionalità del Barocco. Atti del Convegno internazionale promosso dall'accademia delle Scienze di Torino (Torino 1869). Turín, Accademia delle Scienze, 1970, vol. 2, fig. 25); cfr. los tratados del siglo XVI nombrados más adelante en la ref. 15). Ejemplos italianos más antiguos de este esquema son los frescos del coro de la Iglesia Sta. Anastasia en Verona y en el suelo de la Catedral; en los frescos de Girolamo da Milano (actualmente en la Brera de Milano); en la sillería del coro de San Zaccaria en Venecia, etc. L. Fierz-David ha proyectado una escena de la Hypnerotomachia Poliphili (Venecia 1499) sobre este esquema (FIERZ-DAVID, Linda: The Dream of Poliphilo, Nueva York, Pantheon, 1950, pág. 136 y ss.). El rol que nuestra figura tuvo en la Alquimia y Magia de los siglos posteriores se manifiestan p.e. en MS. on vellum, 16th-17th c., Londres, British Library, Add. 36674 (KING, Francis: Magic. The Western Tradition. Londres, Thames and Hudson, 1975, pág. 103); Clavicule de Salomon, siglo XVIII, Biblioteca del Arsenal, Ms 2350 (GRILLOT DE GIVRY, Émile Angelo: Le Musée des sorciers, mages et alchimistes. Paris, Libr. de France, 1929, pág. 96); Cornelius Petraeus, Sylva philosophorum, siglo XVI-XVII, Biblioteca Universitaria de Leiden, Cod. Voss. chym. Q 61 (KLOSSOWSKI DE ROLA, Stanislas: Alchemy. The Secret Art. Londres, Thames and Hudson, 1973, pág. 121). Algunos ejemplos de la tradición oriental se encuentran en MURATORE, Giorgio: La città rinascimentale. Tipi e modelli attraverso i trattati. Milano, Gabriele Mazzotta, 1975, pág. 185 y ss.. El esquema ha sido incluído tanto en los tratados de arquitectura, así como en los diseños de Filarete, por supuesto sin tener la misma importancia: Francesco di Giorgio Martini, cod. Magl. II,I,141, fol. 60v, cfr. fol. 40r; Antonio da Sangallo il Giovane, Diseño de Fortalezas, Florencia, Uffizi, Arch 758; Girolamo Maggi-Castriotto, Della fortificatione della città, Venecia, 1564 , fol. $52 \mathrm{r}$ y52v.

15 El comentario de Clavius está disponible en una moderna edición facsimilar: CLAVIUS, Christoph: In Sphaeram loannis de Sacro Bosco Commentarius. Nachdruck der Ausgabe Mainz 1611. KNOBLOCH, Eberhard (ed.), Hildesheim, Olms-Weidmann, 1999 (pág. 17 el esquema de elementos y cualidades). Clavius copió esta figura de Oronce Finé, Protomathesis, Paris, 1532 (HENINGER, S.K., Jr.: The Cosmographical Glass. Renaissance Diagramms of the Universe. San Marino/Calif., Huntington Library, 1977, fig. 64 en pág. 


\section{Q: artículos $\quad$ Berthold Hub}
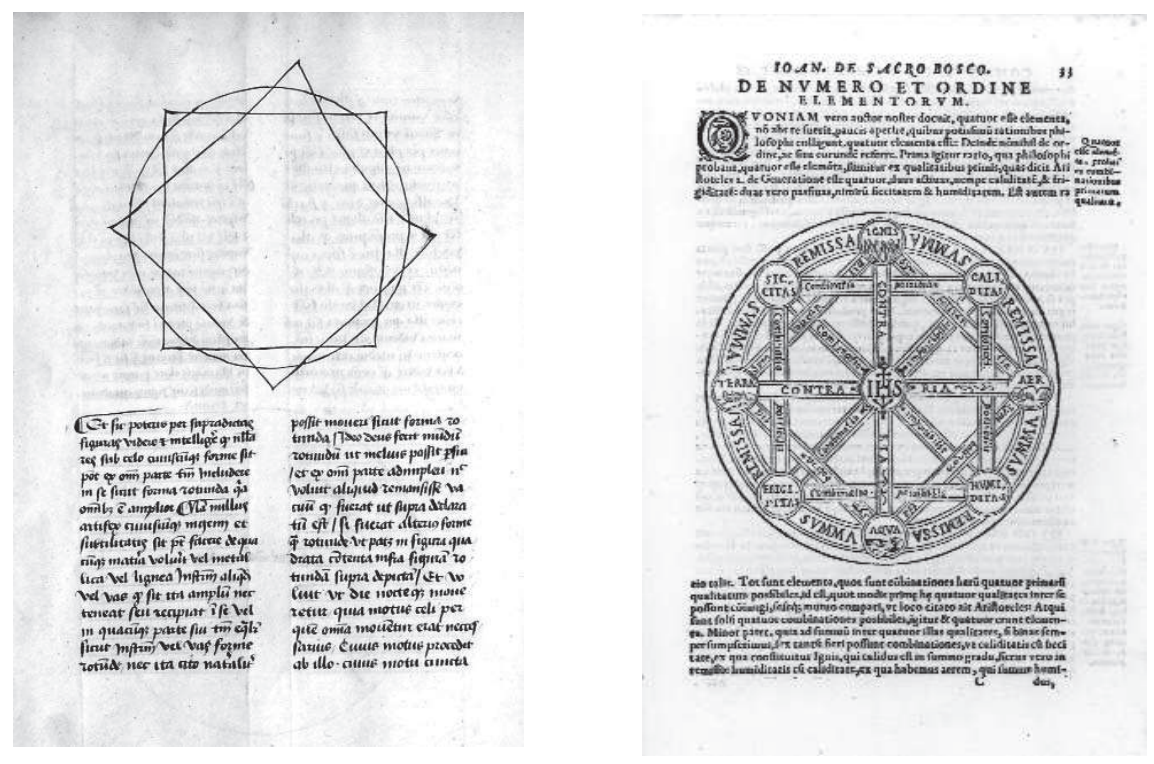

5. LUDOVICUS DE ANGULO: "De Astrologia”, c. 13. Kantonsbibliothek St. Gallen, Vad. Slg. Ms. 427, fol. $7 v$.

6. ChRISTOPHORUS ClaVIUS: In Sphaeram Ioannis de Sacro Bosco Commentarius, Romae, Victorius Helianus, 1570, pág. 33. Oesterreichische Nationalbibliothek, Wien.

por la mayoría de los científicos del Renacimiento precursores de Paracelso ${ }^{17}$.

La parte del tratado de Filarete que se refiere al plano urbanístico no contiene nada que indicara de forma explícita la intención de Filarete de crear un esquema como representación del mundo, pero su interés en la astrología y en las relaciones macrocósmicas se ve plasmado en numerosos pasajes de su tratado.

El nexo entre el ordenamiento macrocósmico y el microcosmo de la ciudad aparece en la descripción del castillo principesco en el sexto libro, justo después de la construcción de la muralla de la ciudad y antes de la disposición del conjunto de plazas en el centro de la ciudad ${ }^{18}$. La construcción está rodeada por un laberinto y se divide en cuadrados equiláteros con una medida de tres por tres. En su centro, se

106); cfr. Michael Scotus, Commentarius in Sphaeram mundi Joannis de Sacrobosco, Venecia, 1518; y Charles Bouelles, Liber de generatione, Paris, 1532 (HENINGER, S.K., Jr.: op. cit., fig. 63c en pág. 106).

16 Antetodo en De generatione et corruptione y en la Meteorologica.

17 HENINGER, S.K., Jr.: op. cit.; Idem: "Some Renaissance Versions of the Pythagorean Tetrad", Studies in the Renaissance $n^{\circ}$ 8, Nueva York, 1961, págs. 7-35; Idem: Touches of Sweet Harmony. Pythagorean Cosmology and Renaissance Poetics. San Marino/Calif., Huntington Library, 1974.

18 Libro VI, fol. 37v-42r; ANTONIO AVERLINO "FILARETE": op. cit., págs. 111-119 (la descripción de la torre en fol. 41v-42r, 72; Ibid., pág. 117 y ss.). 
eleva una torre que representa el transcurso del año de diferentes maneras: los cuatro elementos de construcción que se encuentran superpuestos uno sobre el otro, representan las cuatro estaciones del año y tienen la misma cantidad de ventanillas como el año cuenta días al igual que la misma altura en braccia (es decir, 365, aprox. 183 metros). Finalmente, la torre se divide por una cornisa después de cada 30 braccia. De ésta manera también quedan representados los doce meses del año. Esta edificación parece ser aquella torre que Filarete en el segundo libro había pensado disponer en la mitad de la plaza central, es decir en la mitad exacta de la construcción urbana centrada y simétrica que se eleva hacia el centro, y que en ése lugar hubiera hecho recuerdo a la vieja idea del axis mundi en la montaña del mundo, pero que, sin embargo, ya no vuelve a ser mencionada en la descripción detallada de la plaza central en el sexto libro ${ }^{19}$. Por lo visto, Filarete dejó de orientarse en el plano ideal original para adoptar una orientación centrada en ejemplos de la vida real. El reconocimiento de la verdad urbana y de sus necesidades, se ha traducido en una supresión de la idea originaria, pero no en su renuncia total. El proyecto se realiza como elemento de construcción central de un castillo, cuya función y emplazamiento exacto dentro de la ciudad no queda indefinido por casualidad20. Además, lo que ambos proyectos tienen en común, es la idea de un acueducto que transporta agua desde las afueras hacia el centro de la ciudad. Sin embargo, este agua ya no corre por los canales y las calles de la ciudad, sino por las vías del laberinto, que rodea al castillo. Este laberinto no sólo es símbolo tradicional del alto arte del arquitecto, sino

\footnotetext{
19 Cfr. antetodo KAUHSEN, Bruno: Omphalos. Zum Mittelpunktsgedanken in Architekur und Städtebau dargestellt an ausgewählten Beispielen. Munich, Scaneg, 1990. Posiblemente Filarete también se inspiró en la conocida torre de Alberti (De re aedificatoria VIII, 5); o en las representaciones de la Civitas terrena de Augustín (cfr. p.e. DE LABORDE, Alexandre: Les manuscrits à peinture de la Cité de Dieu. Paris, E. Rahir, 1909, vol. 3, pl. LXX); además en la descripción en el Picatrix de una torre de señalización giratoria y con connotación cosmológica del castillo de la ciudad egípcia Adocentyn, construída por Hermes Trismegistos (cfr. YATES, Frances: Giordano Bruno and the Hermetic Tradition. Londres, Routledge, 2002, pág. 57 y ss.; en el Libro XXI, fol. 171r de Filarete también se habla de una torre giratoria; ANTONIO AVERLINO "FILARETE”: op. cit., págs. 349). Una construcción de torre central o un templo en concordancia con la tipología de Filarete, se convierte rápidamente en un elemento sólido de la literatura utópica, que no se deja influenciar por obligaciones funcionales y por ideas utilitarias, sino que convierte el centro de la ciudad en el símbolo de referencia (Anton Francesco Doni, Bartolommeo Delbene, Tommaso Campanella, Johann Valentin Andreae entre otros), pero también puede ser encontrado en diseños de los arquitectos (Fra Giovanni Gioconda, Baldassare Perruzzi, Antonio da Sangallo el Joven, un proyecto no terminado para Palmanova, etc.). El conjunto de plazas termina siendo en la obra de Filarete un cuerpo extraño, tanto en el aspecto formal como en la práctica. El distanciamiento de la torre originalmente prevista para el centro de la ciudad, no sólo significa una pérdida de significado, sino que también representa una contradicción entre el conjunto irregular de las plazas y la delimitación rígida de la ciudad en su totalidad, e impide en el futuro el enlace orgánico de las (dieciseis) calles y canales radiales con el conjunto irregular de plazas.

20 Cfr. MARCONI, Paolo: "Il problema della forma della città nei teorici d'architettura nel Rinascimento", Palladio. Rivista di Storia dell'Architettura n²2, Roma, 1972, pág. 55 y ss., y MARCONI, Paolo et al.: La città come forma simbolica. Studi sulla teoria dell'architettura nel rinascimento. Roma, Bulzoni, 1973, pág. 63 y ss. La teoría de M. Fagioli dell'Arco (FAGIOLI DELL'ARCO, Marcello: "Il castello delle meraviglie. Nuove ipotesi sulla genesi di Sforzinda e su Galisforma", Quaderni dell'istituto di storia dell'architettura n.s. fasc. 1-10 Roma, 1983-1987, págs. 187-196 (Saggi in onore di Guglielmo De Angelis d'Ossat. BENEDETTE, Sandro y MIARELLI, Gaetano (eds.), Roma, Multigrafica Ed., 1987), según la cual Filarete emplaza el castillo principesco más allá de las murallas de la ciudad de Sforzinda, no se ha podido demostrar en conformidad al texto.
} 
que también sirve como protección del centro mágico, al que sólo accederá el Duque mediante un puente ${ }^{21}$. Queda abierto si las vías pueden ser consideradas como una ilustración del movimiento de los planetas. Lo que sí podemos resaltar, es que no sólo este laberinto entre los cuatro mencionados en el tratado de Filarete, sino que otros dos más, son caracterizados por siete corredores 22 . Dos de ellos como en este caso, sirven nuevamente como base para un castillo principesco23. El cuarto laberinto está rodeado por un muro cuadrado que dentro de sí incluye un jardín en forma circular que representa en su disposición un mapa mundi. En las torres de cada esquina del muro se encuentran representaciones de los cuatro vientos principales. Al medio del jardín hay otra vez un palacio, construído otra vez en una planta de tres por tres ${ }^{24}$.

Volvemos a encontrar una connotación parecida macrocósmica en relación a la combinación del círculo con el cuadrado en la Catedral de Sforzinda construída sobre una cruz griega ${ }^{25}$. Mientras que la cúpula semi-esférica está rodeada por rayos dorados en fondo azul, el cuadrado de la intersección de la nave inscribe la representación correspondiente circular de los continentes y de los océanos dentro de los doce signos de los meses y de los zodiacales, teniendo el mismo diámetro de la cúpula. En los brazos laterales de la cruz griega, igualmente en forma cuadrada, encontramos los cuatro elementos así como las estaciones del año.

Como último ejemplo a mencionar para las relaciones micro y macrocósmicas omnipresentes en el tratado de Filarete, queremos señalar la decoración del Palacio del Duque ${ }^{26}$. En las pinturas y mosaicos del pórtico del patio interior, al lado destinado para su utilización por la duquesa, se ilustran los cuatro elementos a través esce-

21 Acerca del laberinto como símbolo del arquitecto cfr. sobretodo KERN, Hermann: Labyrinthe. Erscheinungsformen und Deutung. 5000 Jahre Gegenwart eines Urbildes. Munich, Prestel, 1982, pág. 271 y ss., y REED DOOB, Penelope: The Idea of the Labyrinth from Classical Antiquity to the Middle Ages. Ithaka, Cornell University Press, 1990, pág. 66 y ss.; cfr. el nombramiento repetido de Daidalos, conocido tradicionalmente como el maestro de construcción del laberinto cretense y como pionero de los arquitectos; en el Libro $\mathrm{VI}$, fol. 38r se menciona a Daidalos en el contexto de la discusión de la planta del laberinto que rodea la torre del castello. De aquí también surge la denominación en las lenguas romances de laberinto o jardín de la perdición como "dédalo", etc. hasta el día de hoy. Sobre la función protectora del laberinto cfr. KERN, Hermann: op. cit., pág. 108 y ss., y REED DOOB, Penelope: op. cit., pág. 72 y ss.

22 Cfr. KERN, Hermann: op. cit., pág. 30 y ss., sobre los aspectos cosmológicos y astrosimbólicos del laberinto. La división de la plana cuadrada en nueve cuadrados inferiores, con la sede del gobernante en el cuadrado central se conoce sólo de la tradición china, por ejemplo en la plana del Palacio Imperial de la antigua China con la Casa del Calendario Ming-t'ang en el centro, desde donde gobernaba el emperador como "hijo celestial" y trataba de crear armonía entre el cielo y la tierra (lo que también se expresa en la arquitectura misma de la Ming-t'ang, a través de la cúpula circular sobre la plana cuadrada); WHEATLEY, Paul: The Pivo of the Four Quarters. A Preliminary Enquiry into the Origins and Character of the Ancient Chinese City. Edinburgh, Edinburgh University Press, 1971, pág. 411 y ss.; cfr. MARCONI, Paolo [et. al.]: op. cit., pág. 65 y ss

23 Libro VI, fol. 38r y fol. 40v (ANTONIO AVERLINO "FILARETE": op. cit., págs. 112 y 116); Libro XIII, fol. 99r (Ibid., pág. 225); Libro XIV, fol. 110r (Ibid., pág. 243). En forma parecida también manifestado un siglo después en las obras del constructor de fortalezas bolognés Francesco de Marchi (Architettura Militare; KERN, Hermann: op. cit., fig. 347 y ss.).

24 Libro XV, fol. 120r-122r; ANTONIO AVERLINO "FILARETE": op. cit., pág. 262 y ss.

25 Libro IX, fol. 64r-66v; ANTONIO AVERLINO "FILARETE": op. cit., págs. 157-161.

26 Libro IX, fol. 67v; ANTONIO AVERLINO "FILARETE": op. cit., pág. 262 y ss. 
nas mitológicas y hechos históricos. En el piso representaciones relacionadas con el elemento tierra rodean otras relacionadas con el elemento agua, mientras que la bóveda lleva representaciones de los elementos contrarios a la tierra y el agua, los del aire y del fuego. Las escenas mitológicas incluídas parecen representar la transición o la unión de un elemento del piso con uno del techo, así como por ejemplo en el caso del robo de Ganymed, que une los elementos opuestos de tierra y aire, o en la caída de Ícaro o la de Phaeton que unifican los elementos contrarios de fuego y agua. La intención de esta decoración obviamente es la representación de la creación, la descomposición y la transmutación de la materia, tal vez incluso la de los procesos del opus alquímico 27 . En la bóveda de la loggia en la parte trasera del espacio dedicada al Duque y que da al jardín, "se deben hacer a semejanza del cielo, lleno de estrellas de oro sobre fondo azul (...) todos los signos del cielo y los planetas y las estrellas fijas"; en el suelo sin embargo, "que se hagan en primer lugar las cuatro estaciones del año y luego los cuatro elementos y la descripción de la tierra (...) ya que en las bóvedas haremos los signos celestes" 28 . Este ciclo cosmológico es complementado a través de representaciones en la fachada de "todos los astrólogos y matemáticos que han inventado las ciencias de medición de los cielos y la tierra"29.

En la conocida edificación pedagógica de Filarete, la "Casa de las virtudes y de los vicios", la última planta se reserva para la astrología, así que esa es demostrada como la ciencia más alta por excelencia ${ }^{30}$. Por esa razón esta ciencia no falta en la gran gama de las ciencias en las que el arquitecto deberá tener un conocimiento, "porque cuando dispone y hace una cosa, debe saber comenzarla bajo un buen planeta y una buena constelación"31. Así como el hombre se encuentra bajo la influencia de los planetas, esto ocurre de la misma manera con cada edificio así como con ciudades enteras ${ }^{32}$. Filarete incluso llega a tal extremo de compa-

27 Según SINISI, Silvana: “II Palazzo della Memoria”, Arte Lombarda n 38, Milano, 1973, pág. 154 y ss.

28 Libro IX, fol. 67r; ANTONIO AVERLINO "FILARETE": op. cit., pág. 261 y ss.

29 Libro IX, fol. 67r; ANTONIO AVERLINO "FILARETE": op. cit., pág. 263.

30 Libro XVIII, aquí fol. 145r; ANTONIO AVERLINO "FILARETE": op. cit., pág. 306; el hecho de que a la astrología se le confiera el último piso de los siete que se les dedica a las artes liberales, no sólo tiene su justificación práctica, sino que el paso de una ciencia a la siguiente, se caracteriza al mismo tiempo como un avance en la virtuosidad.

31 Libro XV, fol. 113r-113v; ANTONIO AVERLINO "FILARETE": op. cit., pág. 252

32 Libro I, fol. 2v; ANTONIO AVERLINO "FILARETE": op. cit., pág. 51: "Como todos saben, el hombre fue creado por dios. (...) Y también, a su modo, concedió al ingenio de ese hombre hacer diversas cosas para su vida y placer, $y$, según se ve tener más ingenio uno que otro, quién en una facultad y quién en otra, y unos más y otros menos, según se ve todos los días que ocurre entre los hombres. Y esto muchas veces es a causa de las constelaciones celestes, y también según el planeta la naturaleza produce a uno más industrioso que otro, según le place..." (cfr. Libro I, fol. $5 r$ et seq.; ANTONIO AVERLINO "FILARETE": op. cit., pág. 54: "No se puede negar que hay muchas y diversas clases de personas y calidades (...) que veas en los edificios el mismo efecto. Jamás has visto edificios, quiero decir casas o moradas, que fuesen totalmente iguales..."). Cfr. Libro I, fol. 6r-7r, aquí fol. 6r; ANTONIO AVERLINO "FILARETE": op. cit., pág. 56 y ss. "Podrías decir: 'Pero también se muere aunque se coma.' También el edificio decae por efecto del tiempo. $Y$ unos mueren antes que otros, y tienen menos salud, lo cual muchas veces ocurre por la complexión, es decir, por haber nacido bajo un planeta o en tal o tal otro punto. Del mismo modo el edificio se arruina antes o después según sea la bondad de sus materiales, e incluso bajo qué planeta y punto se edifica. (...). Basta con esto 
rar la concepción y la construcción de una ciudad con la creación y el nacimiento de un niño ${ }^{33}$. Si existe la posibilidad de elaborar una carta natal para el ser humano, entonces habrá que buscar el momento propicio también para las edificaciones humanas en miras a su futuro.

Aunque la astrología es considerada como parte necesaria del conocimiento del arquitecto, luego es un especialista, un astrólogo de la Corte que es encargado por Francesco Sforza con la tarea de determinar el momento propicio para sentar la primer piedra de la construcción ${ }^{34}$. Éste concluye lo siguiente: "El buen día y el buen punto para la construcción de la ciudad y para poner la primera piedra será, en este año sesenta el día 15 de abril, a las diez y veinte. En aquel momento será ascendente un signo fijo de la tierra elevándose el Sol..."35. La entrada del sol en Aries, el pri-

para entender que el edificio vive e muere y es ayudado a vivir y a morir como le ocurre al hombre, es decir, al cuerpo del hombre."; parecido en el Libro VII, fol. 47r. Cfr. Libro IV, fol. 25v; ANTONIO AVERLINO "FILARETE": op. cit., pág. 85, en donde Filarete deja una caja junto a la primera piedra del fundamento de la muralla de la ciudad, que aparte del libro de bronce contiene "un vaso de piedra lleno de mijo, o de trigo, quiero decir de grano, cuya tapa es una imagen de Cloto y de Láquesis y de Atropos, y sobre el cual sólo está escrito 'vida y muerte'. He preparado también un vaso de vidrio lleno de agua, y uno lleno de vino, y uno lleno de leche, y uno lleno de aceite, y uno lleno de miel. (...) La razón por la que pongo estas cosas en el fundamento es que, como saben todos, todo lo que tiene un principio debe tener un fin. (...) Este vaso significa que una ciudad debe ser como un cuerpo humano, y por eso debe estar llena de aquello que da la vida al hombre...".

33 Libro II, fol. 7v; ANTONIO AVERLINO "FILARETE": op. cit., pág. 61: "Tal vez podrías decirme: "me has dicho que el edificio se parece al hombre. Pues, si es así, hay que engendrarlo, y luego parirlo, como al hombre'. Y así es: el edificio primero se engendra y luego nace. Lo podrá entender por comparación: es como cuando la madre pare a su hijo al cabo de nueve meses, o a veces de siete, y lo hace crecer con buen orden y solicitud. - Dime, ¿cómo se produce esta concepción? - La concepción del edificio es de la siguiente forma: así como nadie puede engendrar a otro sin el concurso de la mujer, del mismo modo el edificio no puede ser creado por uno sólo; y así como no se puede engendrar sin mujer, del mismo modo el que quiere edificar necesita tener un arquitecto y engendrarlo con él. Y luego el arquitecto tiene que parirlo, y cuando lo ha parido, el arquitecto viene a ser la madre del edificio. Pero antes de parirlo, del mismo modo que la mujer - come te he dicho antes lleva el feto en el cuerpo nueve o siete meses, asi el arquitecto debe fantasear y pensar durante nueve o siete meses y darle vueltas en su mente de diversos modos, y hacer diversos diseños mentales sobre la concepción que ha realizado con el patrón, según la voluntad de éste. Y así como la mujer nada hace tampoco sin el hombre, así el arquitecto es la madre aquel lleva esta preñez. Y según su deseo, cuando lo ha rumiado y considerado bien y pensado de muchas maneras, debe luego elegir aquel que le parezca más adecuado y hermoso según los designios del que lo ha engendrado. Y hecho esto, parirlo..."

34 Filarete no nombra al astrólogo de la Corte, tal vez pensó en Battista Piasio, un teólogo y astrónomo augustino, al que Francesco Sforza había mandado llamar justo antes para servirle en su Corte; éste no sólo había comentado la Sphaera de Sacrobosco, sino que era conocido por sus predicciones de acontecimientos futuros y por sus pronósticos anuales (cfr. THORNDIKE, Lynn: A History of Magic and Experimental Science. Nueva York, Columbia University, 1934, vol. 4, pág. 458 y ss.). Sin embargo, Francesco Sforza también se sirvió de otros astrólogos. En el año 1451 encomendó a tres de ellos para determinar el momento más adecuado para la toma del Castello di Porta Giovia en Milano. En la correspondencia correspondiente se nombran las siguientes fechas importantes: la fecha de nacimiento del propio Duque y el de su capitán, así como la fecha de la construcción del Castello (BELTRAMI, Luca: /l Castello di Milano durante il dominio dei Visconti e degli Sforza 1368-1585. Milano, U. Hoepli, 1884, pág. 99 y ss.; cfr. CASTELLI, Patrizia: “Caeli enarrant': Astrologia e città", en Le città di fondazione. Atti del $2^{\circ}$ Convegno internazionale di storia urbanistica (Lucca 1977). MARTINELLI, Roberta y NUTI, Lucia (eds.), Lucca, II Ciscu, 1977, pág. 186). Galeazzo Maria Sforza también le dio empleo a varios astrólogos (LUBKIN, Gregory: Renaissance Court. Milan under Galeazzo Maria Sforza. Berkeley, University of California Press, 1994, pág. 116 y ss.; cfr. THORNDIKE, Lynn: op. cit., pág. 263 y ss. y pág. 439)

35 Libro IV, fol. 24v-25r; ANTONIO AVERLINO “FILARETE”: op. cit., pág. 84 y ss. El texto continúa: "Venus, 
mer signo que domina entre el 21 de marzo hasta el 20 de abril, como el momento más indicado para la construcción de edificaciones y ciudades por el hombre es una suposición tradicional ${ }^{36}$. No es fortuito que coincida con aquella sobre la constelación de los planetas en el momento de la creación del mundo por Dios ${ }^{37}$. Esto nos hace suponer que los esquemas cuadrados del horóscopo que predominaban tanto en la Edad Media como en el Renacimiento, con su sistema dodecanario de Casas y Signos, se derivan de la construcción en ocho partes de los cuadrados superpuestos de las tetradas elementales y cualitativos, respectivamente, la cual, tal como ya hemos

la fortuna, estará en signo fijo terrestre: el hecho de que ésta esté en signo fijo, y el señor en ascendente es venturoso, porque está en su casa y en la ascendente. La luna en aquel mismo punto estará en medio del cielo, recibida en la casa de Saturno, la cual tiene gran virtud para la edificación de la ciudad, propiciada por el aspecto trino de Júpiter con la mayor fortuna. Saturno también es propicio en su propia casa en aque mismo punto, colocado en la décima casa y señor de la casa de la Luna; la parte de la fortuna de la décima casa respecta a la cumplida amistad, es decir, al espectro trino de Júpiter. Por todo lo dicho, este día y hora es apto y debe ser elegido como comienzo de la construccion de dicha ciudad."

36 La contemplación de la constelación planetaria durante la edificación de ciertas construcciones o ciudades es una práctica antigua mencionada en un sinfín de fuentes. Su importancia para la Edad Media y para la Edad Moderna queda comprobada a través de numerosos libros didácticos de astronomía (p.e. por Guido Bonatti y Cecco d'Ascoli, o Nicolas Oresme ex negativo, cfr. sobretodo CASTELLI, Patrizia: op. cit., págs. 173-193; además THORNDIKE, Lynn: A History of Magic and Experimental Science. Nueva York, Columbia University, 1923 y ss., vol. 2, pág. 825 y ss. y pág. 954 y ss.; vol. 3, pág. 399 y ss.; vol. 4, pág. 137; Idem: The Sphere of Sacrobosco and Its Commentators. Chicago, University of Chicago Press, 1949, págs. 343411, antetodo pág. 375; BAIGENT, Michael et al. (eds.): Mundane Astrology. Londres, Aquarian, 1992, pág. 262 y ss.), así como a través de los cronistas de algunas ciudades (p.e. Rinuccini: Florencia florece porque su reconstrucción había sido iniciada bajo Carlos el Grande "a dí primo d'aprile alle diciasette ore dopo il meriggio, ascendente l'Ariete casa di Marte e principio del Zodiaco...”; citado según CASTELLI, Patrizia: op. cit., pág. 191 y ss.). También Alberti aconsejó iniciar la construcción bajo un buen omen y en equilibrada constelación planetaria (De re aedificatoria I,6 y II,13; sobre la posición de Alberti frente a la astrología cfr. NEWMAN, William R. y GRAFTON, Anthony (eds.): Secrets of Nature. Astrology and Alchemy in Early Modern Europe. Cambridge/Mass., MIT Press, 2001, pág. 5 y ss.); al igual que Francesco di Giorgio Martini (Trattati di architettura ingegneria e arte militare. MALTESE, C. (ed.): Milano, II Polifilo, 1967, vol. 2, pág. 294 y ss.) y Francesco de Marchi (Architettura militare I,19; cfr. DE LA CROIX, H.: "Military Architecture and the Radial City Plan in Sixteenth Century Italy", Art Bulletin n 42, Nueva York, 1960, pág. 285 y ss.). Muchas veces sólo se resalta la influencia de los planetas para el destino de edificaciones y ciudades en general, sin embargo si se habla de la constelación más propicia, entonces se trata siempre de la entrada del Sol en el primer grado del signo Aries. Parece que también se llevaron a cabo discusiones acerca del momento más propicio para los trabajos de fundamentación del Ospedale Maggiore en Milano, encargados a Filarete por Francesco Sforza, ya que éstos se efectuaron según nuestro texto el 4 de abril (de 1456; sin embargo Filarete señala una inscripción de una columna delante del hospital el 12 de abril); cfr. p. e. LAZZARONI, M. y MUÑOZ, A.: Filarete. Scultore e architetto del secolo XV. Roma, W. Modes, 1958, pág. 185 y ss., aquí pág. 187. La descripción de las ceremonias que acompañaban la celebración de la fundamentación de Sforzinda en Antonio Averlino..., libro XI, fol. 83v, pág. 192), que por lo general se rige al ejemplo del Ospedale Maggiore, parece ser un relato fiel de la colocación de la primera piedra del hospital milanés.

37 El thema mundi, el horóscopo mundial o la posición asumida de cada planeta al inicio del mundo, se da, cuando el Sol se encuentra en el signo de Aries, señalado incluso por los babilones (y representa simultáneamente el inicio del año babilónico). Según Albumazar, la creación del mundo ocurrió hallándose en conjunción los siete planetas en el primer grado de Aries (en De magnis coniunctionibus, así como en la Introductio ad astronomiam; sobre todo en la posterior, que fue traducida en 1130 al latín y tuvo mucha acogida en el mundo occidental). Parecido, Firmicus Maternus, Mathesis III,1. Cfr. ALBERTI, Leon Battista: De re aedificatoria II,13: "Alcuni però vogliono che la construzione sia iniziata in modo propizio, essendo di grande importanza sapere in quale momento ogni cosa sia entrata nel novero delle cose esistenti..." E tanta influenza fu attribuita dagli antichi sapienti a questo punto d'inizio sugli avvenimenti successivi, che - come 
comprobado, fue descrita en los libros didácticos sobre la astrología de ésa época como la abstracción del cosmos ${ }^{38}$.

Este patrón es la idea arquetípica en la mente de la deidad creadora y como tal la disposición geométrica del cosmos. Pero no sólo nos provee el modelo para el cosmos como el todo, sino que marca su forma en cada nivel de la creación, de manera que todas las cosas son creadas ad similitudinem archetypi (Sacrobosco). Como consecuencia surge una red detallada de correspondencias entre los diferentes niveles de la creación. Esta es la base ideal para la teoría de correspondencia del micro y macrocosmos en su conjunto y la primera base para la epistemia del Renacimiento. Ernst Cassirer la ha traducido en una imagen adecuada:

"El mundo se parece a un cristal que, sin importar en cuantos y cuán pequeños pedazos uno lo divida, siempre deja reconocer la misma forma de organización característica ${ }^{39 " . ~}$

Una visión del mundo estructurada como ésta, en la cual la forma del conjunto del mundo se repite en sus propias subpartes, requiere de un complejo sistema de pensamientos", que no se apoya tanto en las causalidades físicas, sino que trata de explicar la naturaleza y sus procesos siguiendo el principio de la identidad sustancial, de la correlación, de la analogía y de la simpatía. De una ley así, de estructural unidad de

riferisce Giulio Firmico Materno - alcuni cedettero di avere scoperto dall'andamento della storia la data di nascita del mondo, del che diedero notizia con dotte trattazioni..."; ALBERTI, Leon Battista: L'architettura. ORLANDI, G. (ed.): Milano, II Polifilo, 1966, pág. 166. Cabe resaltar las órdenes emitidas poco después por Marsilio Ficinio para la producción de talismanes. En el capítulo "De fabricandi universi figura" de su tercer Libro della Vita ("De vita coelitus comparanda") dice: "Through it (an image of the very universe itself), they seem to hope for a benefit from the universe. The adherent of these things, if he can do it, should sculpt an archetypal form of the whole world, if he pleases, in bronce; he should imprint this subsequently at the right time in a thin gilded plate of siver. But when exactly should he imprint it? When the Sun reached the first minute of Aries. For astrologers customarily tell the fortune of the world - at least, what is going to happen in that year - from this moment, since it is the return of its birthday. He should therefore imprint this figure of the whole world on the very birthday of the world." Libro della Vita III,19; FICINO, M.: Three Books on Life. KASKE, C. V. y CLARK, J. R. (eds.): Binghamton/Nueva York, Center for Medieval \& Early Renaissance Studies, 1989, pág. 343 y ss.; en relación a cómo hay que entender esta visión del mundo "arquetípica" no se nos revela; será que Ficinio supone como sobreentendido el conocimiento del mismo? Entonces, realmente podría tratarse de la figura de dos tetradas superpuestas y encerradas por un circulo a la que nos hemos dedicado con énfasis.

38 Acerca del esquema utilizado en el siglo XV cfr. p. e. LEO, A.: Casting the Horoscope. Londres, L. N. Fowler, 1969, pág. 110 y ss.; NORTH, J. D.: Horoscopes and History. Londres, Warburg Institute, 1986, pág 1 y ss.; MIRTI, G.: "Una introduzione all'astrologia genetliaca", en BINI, D. y MILANO, E. (eds.): Astrologia. Arte e cultura in età rinascimentale. Modena, II bulino, 1996, pág. 245 y ss.

39 CASSIRER, E.: Die Begriffsform im mythischen Denken. Leipzig, Teubner, 1922, pág. 29 y ss., aquí pág. 34; cfr. FOUCAULT, M.: Les mots et les choses. Un archéologie des sciences humaines. Paris, Gallimard 1993, sobretodo pág. 32 y ss.; VICKERS, B. : "On the Function of Analogy in the Occult", en MERKEL, I. y DEBUS, A. G. (eds.): Hermeticism and the Renaissance. Intellectual History and the Occult in Early Modern Europe. Washington, Folger Shakespeare Library, 1988, págs. 266-292, y LEINKAUF, T.: "Interpretation und Analogie. Rationale Strukturen im Hermetismus der Frühen Neuzeit”, en TREPP, A. Ch. y LEHMANN, H. (eds.): Antike Weisheit und kulturelle Praxis. Hermetismus in der Frühen Neuzeit. Göttingen, Vandenhoek \& Ruprecht, 2001, págs. 41-46. 
efectismo, el hombre también puede disponer activamente. De esta manera, la emanación cósmica se encuentra con la capacidad del hombre -gracias a la captación de los nexos estructurales entre el macro y microcosmos- de influir por su parte el mundo superior y de apoderarse de sus fuerzas, a lo que aspira el arte de la magia, al igual que continuar y perfeccionar, modificar o volver a establecer la creación divina en la naturaleza, que es el objetivo del arte alquímico. La magia y la alquimia se muestran de esta manera como parte activa de la captación de la naturaleza, como la parte práctica de una visión del mundo basado en la correlación. Lo que en primer lugar une las ciencias de la astronomía y alquimia por una parte, con las teorías del arte mágico y alquímico por otra, pues es el esquema de elementos y de cualidades cuádruples cómo se nos ha presentado en los tratados astronómicos de aquella época.

Esta figura se adoptó en la alquimia a través de la teoría de la materia de Aristóteles, según la cual los elementos no se distinguen en cuanto a su materia o sustancia (hyle) sino sólo en cuanto a su forma o cualidad (morphe), y por lo tanto son convertibles entre si ${ }^{40}$. Según Aristóteles, todas las cosas perceptibles por los sentidos están compuestas de materia no determinada (la materia primaria del caos original) y de sus cualidades correspondientes, que por su lado pueden ser clasificados como necesarios (esenciales) y como coincidenciales, irrelevantes (es decir accidentales). En conclusión, los elementos aristotélicos son diferentes formaciones de la misma materia primaria, pero cada vez con parejas de cualidades esenciales y contrarias: la tierra es fría y seca, el agua es húmeda y fría, el aire es caliente y húmedo y el fuego es caliente y seco. Estas cualidades pueden variar y al ser esenciales, con esto los elementos también se transforman en otros elementos. Esta transmutación es posible gracias al hecho de que cada elemento comparte una misma cualidad con otro elemento: la tierra y el agua comparten el frío, el agua y el aire comparten la humedad, el aire y el fuego comparten el calor y el fuego y la tierra comparten la sequedad. Por consiguiente, si uno cambia la proporción y la combinación de estos elementos en un cuerpo, surge uno nuevo.

Los alquimistas adoptaron en principio la doctrina aristotélica de los elementos y cualidades, ya que explicaba en teoría la posibilidad del refinamiento y la transmutación de los metales. Sin embargo se distanciaban de Aristóteles al afirmar que la materia primaria (materia prima) sin propiedades se podía aislar 41 . Donde se encontró con otra teoría sobre la materia, specialmente la doctrina árabe del azufre

40 Cfr. Meteorologica I y IV,1; De generatione et corruptione II,3-4, y De coelo II, 7.

41 No existe una buena monografía completa sobre las bases y la historia de la Alquimia, en mi opinión lo mejor me parece COUDERT, A.: Alchemy. The Philosopher's Stone. Londres, Wildwood House, 1980; cfr. SHUMAKER, W.: The Occult Sciences in the Renaissance. A Study in Intellectual Patterns. Berkeley, University of California Press, 1979, pág. 160 y ss.; también recomendable THORNDIKE, L.: A History of Magic and Experimental Science. Nueva York, Columbia University, 1923 y ss., vol. 2-4; muy útil como breve resumen son también las dos obras de referencia ABRAHAM, L.: A dictionary of Alchemical Imagery. Cambridge, Cambridge University Press, 1998, y PRIESNER, C. y FIGALA, K. (eds.): Alchemie. Lexikon einer hermetischen Wissenschaft. Munich, Beck, 1998; entre los diferentes estudios a consultar hay que destacar a RUSKA, J.: Tabula Smaragdina. Ein Beitrag zur Geschichte der hermetischen Literatur. Heidelberg, C. Winter, 1926; además MAHDIHASSAN, S.: "Compass as a significant symbol of Alchemy 


2: artículos Berthold Hub

y del mercurio, la que trataremos más adelante, los cuatro elementos también eran vistos como básicos, de los cuales primero se forman los principios del azufre y del mercurio, los que a su vez forman los metales. De todas maneras, los metales inferiores no pueden ser transformados en oro sin ser descompuestos previamente en su sustancia primordial libre de cualidades, que es la materia prima. Por consiguiente, el metal aùn imperfecto primero se debe putrificar y descomponer, en su materia elemental, en la materia primaria. El resultante chaos indiferenciado luego es dividido y separado en sus cuatro elementos: tierra, aire, fuego y agua. Finalmente los aspectos contrarios de los elementos (caliente y frío, seco y húmedo) deben ser reconciliados y unificados sirviéndose cada vez de aquella cualidad que cada elemento tiene en común con el próximo: la tierra es fría y seca, por lo tanto comparte el frío con el agua, que es fría y húmeda, el agua comparte la humedad (o la fluidez) con el aire, que es caliente y fluído, y el aire comparte el calor con el fuego que es caliente y seco. En resúmen, durante el opus alquímico, los cuatro elementos son segregados y combinados de tal manera para crear una forma nueva, más pura, haste que alcance el estado perfecto de oro. Por eso los alquimistas son a menudo considerados los antecesores de la química experimental. Pero las ideas alquimistas en la Edad Media igual que en el periodo del Renacimiento, eran igual de importantes tanto metafísicamente como físicamente. En otras palabras, para muchos alquimistas, el objetivo del opus era la transformación de los metales inferiores en oro y así obtener una inagotable fuente de riqueza. En este caso, la alquimia era vista como un arte que podría perfeccionar la naturaleza y el énfasis se pone sobre el alquimista como el perfeccionador de las imperfecciones de la naturaleza ${ }^{42}$. No obstante, para otros, la meta de la transformación alquimista no era la obtención del oro, sino de una sustancia llamada Piedra Filosofal o quinta essentia.

Ya Aristóteles había postulado aparte de los cuatro elementos del mundo terrestre, en el espacio sublunar, la existencia de un quinto elemento no creado, imperecedero e intransformable que se encuentra fuera del espacio terrestre, en el espacio supralunar, en el ámbito eternamente igual de las estrellas fijas. Este quinto elemento al que se le atribuyó el término de "éter", luego se convirtió en la Piedra Filosofal o quintaescencia de los alquimistas 43 . Ya para Aristóteles este quinto elemento celestial, al igual que el dodecaedro de Platón, simbolizaba el conjunto de los

which as art tries to imitate creation", Hamdard medicus: Quarterly Journal of Science and Medicine $n^{\circ} 29,3$, Karachi, 1986, págs. 3-17.

42 La naturaleza en su ambición por la perfección quiere producir únicamente oro, la sustancia más preciosa del mundo. Todos los demás metales son etapas anteriores en el lento proceso de la producción de oro, o simplemente fracasos. Mientras la naturaleza requiere más de mil años para llevar a cabo una tarea, el alquimista lo hace en un tiempo mucho más reducido gracias a su acceso a los secretos de la creación en su laboratorio. Esta visión fue aplicada luego a otros procesos de la naturaleza, p.e. a la curación de enfermedades. Lo que aquí ocurre, no es una modificación de la naturaleza, sino su imitación y su perfeccionamiento, según la conocida fórmula de Aristóteles: "El arte culmina lo que la naturaleza no es capaz de culminar, en parte imita a la naturaleza." (Física II,8,199 a 15).

43 De Coelo I,3 y IV; Aristóteles mismo nombra este quinto elemento el primero (proton soma). 
cuatro elementos y de las cuatro cualidades sintetizadas en una unidad ideal. El éter no conoce frío ni calor, ni humedad ni sequedad, ni otras propiedades opuestas. Es del todo simple y no se puede transformar en ninguno de los cuatro elementos sublunares. Distanciándose de ellos, dispone del movimiento más perfecto de todos, el movimiento circular uniforme y eterno. La relación entre la quintaescencia con los cuatro elementos y las cualidades por lo tanto corresponde a la relación que existe entre el cielo y la tierra. Según Aristóteles, por eso el quinto elemento nunca puede ser encontrado en la tierra. Sin embargo, los alquimistas reclamaban la quintaesencia como el resultado de su arte. Ahora, el alquimista cesa de ser solamente un colaborador de la naturalezza, sino crea algo que transcende la naturaleza. A veces la función de esta sustancia era considerada como el agente transmutador en la transformación de metales en oro, para otros, era el elixir de la vida, fuente de juventud, longevidad y de sabiduría; en otros casos servía como sinónimo para el resultado obtenido a través de la obra alquimista: el estado de una parte del mundo más allá del reino de la permutación y de la decadencia. Pero siempre cuando se habla de la Piedra Filosofal o de la quintaescencia, se trata de algo que sobrepasa la naturaleza, es decir la creación divina en su estado corrupto.

Una metáfora alquimista utilizada constantemente representa la separación y la consiguiente unificiación de los cuatro elementos y las cuatro cualidades (coincidentia oppositorum) hacia la transcendente unidad armónica, la quintaescencia, ilustrada como la cuadratura del círculo introvertida, que es la transformación del cuadrado (los cuatro elementos y las cuatro cualidades: el mundo material) en el círculo (la quintaescencia: el cielo). Esta es exactamente la figura en la que se basa la plana de Sforzinda y que los tratados astronómicos de aquella época presentaban como la abstracción del cosmos.

Por otro lado, ya en la filosofía natural de la Stoa, a diferencia de Aristóteles, se asumía la existencia de los cinco elementos y sus cualidades también en la esfera supralunar. Pero los elementos del cosmos eran vistos como portadores de principios puros y espirituales, mientras que los elementos terrestres eran considerados como manifestaciones mezcladas, impuras de estos principios, y por lo tanto se mantenía la diferenciación de ambas esferas. Con esto se había modificado la doctrina monástica de la substancia esencial de Aristóteles y se convirtió en una teoría de la relación macro y microscópica. Este nexo entre mundo y cosmos, micro y macro cosmos en el marco de un principio de correpondencia universal se manifiesta de manera más clara en la Tabula samaragdina que se atribuía a Hermes Trismegistos, el misterioso padre de la alquimia, y que se conocía en el occidente por lo menos desde la época de Albertus Magnus. "Lo que se encuentra abajo es aquello que se encuentra arriba, y lo que se encuentra arriba, es lo que se encuentra abajo, para la perfección del milagro de la unica cosa" 44 . Por eso es que los planetas y sus constelaciones tenían que ser considerados tanto al inicio como en los trabajos posteriores de la obra alquimista. 


2: artículos Berthold Hub

Tal como para los astrólogos y para el arquitecto Filarete, los alquimistas también consideraban la entrada del sol en el primer signo Aries como el momento más indicado para el comienzo del opus, porque en ése mismo momento el creador divino había creado el cosmos por su cuenta ${ }^{45}$. Es decir que el alquimista se preocupaba por llevar a cabo su trabajo paralelamente a la creación divina y comparaba su obra microcósmica con el opus del creador del mundo a inicios de los tiempos. Se quería construir la obra alquimista basándose en los mismos principios y con las mismas proporciones del gran mundo, el macrocosmos. Es por éso que en tratados alquimistas se encuentra con frecuencia la denominación de la Piedra Filosofal como un "microcosmos" o un "mundo pequeño"46. La Tabula Smaragdina atribuída a Hermes incluye en la descripción del opus alquimista la observación "de esta manera se creó el mundo" 47 , lo que su comentador más influyente Hortolanus explica de manera siguiente: "Tal como el mundo fue creado, de la misma manera está compuesta nuestra piedra48". En consecuencia los alquimistas no sólo veían su creación como una réplica de la creación de Dios, sino que también percibían la creación divina como un proceso alquímico. Los alquimistas veían a Dios como un alquimista divino que creó un universo ordenado y armonioso a través de un proceso de segregación y conjunción de los cuatro elementos sobre el caos primordial de la materia prima. Es decir que la tarea del alquimista era volver a los secretos de la creación divina del macrocosmos, porque en su opus se veía una réplica o una restauración de la creación originaria de Dios. El último objetivo del alquimista era este nuevo acuerdo entre el micro y macro cosmos, la restauración de la armonía pura del origen antes de la decadencia, el reestablecimiento de la unidad mitológica y la integridad del mundo en el momento de su creación, o la re-creación de la creación divina originalmente armoniosa.

La hipótesis de que Filarete no sólo quería crear una imagen de la estructura concepcional del cosmos, tal como lo podemos ver en los tratados astronómicos de la época, sino que también aspiraba a una re-actualización o re-creación de la primordial creación divina, tal como los alquimistas, posibilitada por el conocimiento

\footnotetext{
44 RUSKA, J.: op. cit., pág. 2 (Segunda oración: "Quod est inferius, est sicut quod est superius, et quod est superius, est sicut quod est inferius, ad perpetranda miracula rei unius."); sobre la Tabula Smaragdina cfr. KAHN, Didier: Hermès Trismégiste. La Table d'Émeraude et sa tradition alchimique. Paris, Les Belles Lettres, 1994.

45 Por ejemplo en Albertus Magnus, De causis proprietatum elementorum I,2,7.

46 P. e. en Petrus Bonus, Pretiosa margarita novella de thesauro ac pretiosissimo philosophorum lapide; BONUS, Petrus de Ferrara: The New Pearl of Great Price. WAITE, A. E. (trans.), 2 ed., Nueva York, Arno Press, 1974, pág. 238: "The stone of the Philosophers ... a microcosm or little world"; cfr. Tractatus Micreris suo discipulo Mirnefindo, en ZETZNER, L. (ed.): Theatrum chemicum.... s.I., Argentorati, 1613 y ss., vol. 5, pág. 388, o Nicolaus de Comitibus: Speculum alchimiae, en ZETZNER, L.: op. cit., vol. 4, pág. 515 y ss. (cfr. THORNDIKE, L.: op. cit., vol. 3, pág. 163 y ss.).

47 RUSKA, J.: op. cit., pág. 2 (frase 10: "Sic mundus creatus est.").

48 HORTULANUS: A Briefe Commentarie of Hortulanus the Philosopher, upon the Smaragdine Table of Hermes of Alchemy, en BACON, R.: The Mirror of Alchimy Composed by the Thrice-famous and Learned Fryer, Roger Bacon (1597). LINDEN, S. J. (ed.): Nueva York, Garland, 1992, pág. 25.
} 
acerca de su estructura, nos testifican las descripciones detalladas de los ritos y los hechos que acompañan la ceremonia de la puesta del primer cimiento en el momento determinado por el astrólogo de la Corte Sforzesca 49 . Aparte de diferentes omenes propicios y ritos exorcistas que tienen la intención de excluir los poderes del caos del cosmos urbano y de asegurar el bienestar y los recursos, se trata sobretodo de imágenes de una cosmogonía, que acompañan este acto de fundación, como por ejemplo el sacrificio de un ser humano, la serpiente como protectora del centro de la vida en el árbol del mundo o la hierogamia cósmica del cielo y de la tierra en la unificación del águila con la serpiente. Todas estas imágenes tienen la intención de trasladar la fundación histórica de la ciudad a dimensiones místicas de la primordial creación del mundo al inicio de los tiempos y así repetir en forma real-simbólica el acto de creación divina. La reactualización de la cosmogonía debe resultar en un retorno a la unidad y la armonía primordial y de tal manera asegurar sabiduría, riqueza y la estabilidad al nuevo cosmos 50 .

Al inicio de las ceremonias de fundación se entierra junto con el primer cimiento un cajón de mármol en el fundamento de las murallas de la ciudad 51 . En ese cajón se había depositado un libro, que deberá dar testimonio "de todas las cosas de esta época nuestra y también de los hombres dignos que las han hecho", pero sobre todo de los propios esbozos y de las arquitecturas de Filarete ${ }^{52}$. La justificación para esta medida hace éxplicit la correspondencia con aquél Libro Dorado antiguo, que más tarde sará encontrado en las excavaciones de las murallas de una segunda ciudad al lado del mar:

“La razón por la que pongo estas cosas en el fundamento es que, como

49 Antonio Averlino... op. cit., Libro IV, fol. 25r-30r, págs. 84-91) y Libro V, fol. 33r (Ibídem., pág. 97); cfr. Libro VI, fol. 41r (Ibid., pág. 117); explicación parcial en Libro VI, fol. 45r-45v (Ibídem., pág. 122 y ss.); cfr. la descripción de las ceremonias durante la colocación de la primera piedra del hospital de Sforzinda en Libro XI, fol. 83v; Ibídem., pág. 192. Sólo SINISI, S.: Filarete nascosto. Salerno, Istituto universitario di magistero, 1971, pág. 27 y ss., le dedica más atención a este acontecimiento, sin profundizar en su simbolismo.

50 A continuación se trata de perennizar la creación educando el pueblo de manera que destaque en él la virtuosidad. La ciudad entera se presenta como un edificio educativo, plataforma de un verdadero orbis pictus, como lo volvemos a encontrar en las posteriores utopías literarias de Caspar Stiblin o Tommaso Campanella. Las pinturas, esculturas y los mosaicos portan frecuentemente inscripciones descriptivas y en el caso de Filarete no sólo sirven para la formación general científica, para la presentación de ídolos y de ejemplos disuasorios de la historia y de la mitología. Sforzinda le da mucha importancia a representaciones que aportarán que los ciudadanos sean concientes de los fundamentos macrocósmicos de la ciudad y de su creación. En este marco cabe resaltar sobre todo aquella fuente en el patio del Palacio del Duque al centro del conjunto urbano (Antonio Averlino... op. cit., Libro IX, fol. 68r, pág. 163 y ss.), que a través de su escultura, su relieve y a través de inscripciones explicativas deberán recordar permanentemente los ritos festejados en aquél lugar, así como los acontecimientos en torno a la fundación de la ciudad y penetrar de esta manera también hasta la conciencia colectiva; cfr. SINISI, S.: "Il Palazzo della Memoria", Arte Lombarda $\mathrm{n}^{\circ}$ 38, Milano, 1973, pág. 158. Sobre el programa educativo de Filarete en el contexto de la literatura utópica cfr. RAHMSDORF, S.: op. cit., sobretodo pág. 53 y ss. En la "Casa de la virtud y del vicio" (Antonio Averlino... op. cit., Libro XVIII; pág. 303 y ss.) la arquitectura se convierte en pedagoga; cfr. BAUER, H.: op. cit., pág. 
saben todos, todo lo que tiene un principio debe tener un fin. Cuando les llegue ese momento, algunos encontrarán estos objetos, y por esto seremos recordados y nombrados por ellos; como hoy, cuando por excavación o ruina se encuentra alguna cosa digna, la estimamos y nos place haber encontrado esa cosa que representa la Antigüedad, y el nombre de los que la han hecho" 53 .

El presente, es decir las arquitecturas y obras de Filarete, tendrán el mismo valor y significado para las próximas generaciones como los que se le atribuye a la Era Dorada de la Antiguedad para la actualidad.

En los trabajos de fundamentación de la muralla de la ciudad porteña llamada Plusiapolis ("ciudad rica") se descubre un tesoro que contiene, entre otras cosas preciosas, un libro dorado redactado en griego 54 . El autor de este Codex Aureus es un rey antiguo llamado Zogaglia, cuya ciudad Galisforma (ambos nombres son desfiguraciones anagramáticas de Galeazzo Maria Sforza) había existido en ese mismo lugar. El relato cuenta la historia de este antiguo rey que, sirviéndose de más anagramas, en realidad termina siendo la historia de la subida al poder de la familia Sforza ${ }^{55}$. Es decir que se trata de una afirmación y de una nobilitación del dominio de los Sforza a través de una proyección al pasado y al ideal de la Antigüedad. Pero también Filarete aparece con dos papeles: como arquitecto de los Sforza y como arquitecto de la Corte del antiguo Rey Zogaglia "Onitoan Nolivera (...) de origen notirenflo" (Antonio Averlino, Florentino), es decir como creador de todas las edificaciones y plantas descritas en el antiguo Libro Dorado. Al final se comienza la construcción de la ciudad porteña de los Sforza recurriendo a las descripciones de una ciudad porteña con todas sus edificaciones correspondientes que se situaba en el mismo lugar, pero que se había sumergido56. Sin embargo, algunas descripciones se refieren a edificaciones ya construidas en la ciudad de Sforzinda situada más al interior del país. Los palacios mencionados entonces vuelven a ser descritos en el Libro Dorado y las iglesias construidas entonces vuelven a ser nombradas. Y realmente, Filarete atribuye al antiguo Rey Zogaglia también la construcción de una segunda

78 y ss.; además HIDAKA, K.: "La casa della virtù e del vizio nel trattato del Filarete”, en GUILLAUME, J. (ed.): Les traités d'architecture de la Renaissance. Paris, Picard, 1988, págs. 115-128, y OPPIO, L.: "La casa della virtù e del vizio del Filarete e le allegorie vinciane del piacere e dispiacere", Achademia Leonardi Vinci ${ }^{\circ}{ }^{8}$, Florencia, 1995, págs. 190-193.

51 Antonio Averlino... op. cit., Libro IV, fol. 24r, pág. 85.

52 Ibídem.

53 Ibídem.

54 Antonio Averlino... op. cit., Libro XIV, fol. 103r y ss., pág. 231 y ss.

55 Tanto en Zogaglia como en Galisforma se oculta el nombre del príncipe Galeazzo Maria Sforza; la suerte de su bisabuelo y de su padre son los hechos realizados por lacopo Mucio (Locuimo) Attendolo, y el camino recorrido por Francesco Sforza para obtener el dominio sobre el país de mayo, desde la victoria sobre el Braccio (Ciobra) da Montone hasta el matrimonio con Bianca Maria, hija de Filippo Maria (Polifiamma) Viconti. 56 La lectura del Libro Dorado a partir del Libro XIV, fol. 103r hasta el Libro XXI, fol. 173r, en Antonio Averlino... op. cit., págs. 231-352. 
ciudad, más al interior del país, donde Filarete acabó de construir la ciudad de Sforzinda por encargo de Francesco Sforza ${ }^{57}$. A esto se suma, que en la lectura del Libro Dorado el diálogo del rey antiguo con su arquitecto, no puede ser distinguido ni siquiera en la forma de aquél diálogo que existe realmente entre Filarete y Galeazzo Maria Sforza; sí, incluso Filarete se olvida de hacer anagramas de los nombres o no lo hace a propósito, para los dos planos temporales ya no sean distinguibles y se unan. De esta manera, Filarete legitimiza y le otorga nobleza a sus propias ideas y diseños siguiéndo el ideal de la Antigüedad y se presenta como creador de una nueva Era Dorada.

Sin embargo, lo que el arquitecto entiende concretamente bajo arquitectura "antigua", la que debe de ser reavivada, en realidad tiene poco que ver con la arquitectura romana, recogida arqueológicamente por Brunelleschi y Alberti y bien conocida por Filarete. Eso se puede ver claramente y a más tardar en las ilustraciones anexas a las descripciones de las edificaciones de Sforzinda, que muchas veces tienen más elementos en común con arquitecturas del Oriente próximo y lejano que con construcciones griegas o romanas de la Antigüedad clásica58. El texto por su parte se refiere varias veces a Egipto como fuente de toda arquitectura y como el

57 El relato de la disputada subida del rey Zogaglia (de Francesco Sforza) termina con la frase: "Así que luego, estando en paz, se deleitó mucho con la arquitectura y construyó muchos y diversos edificios; y sobre todo, en este valle de arriba, no muy lejos de aquí, una gran ciudad. Aquí hicimos juntos, en este lugar, otra ciudad con un puerto magnífico y útil que en sus tiempos se llamaba Limen galenokairen, y la ciudad se llamaba Plousiapolis..." (Antonio Averlino... op. cit., Libro XIV, fol. 104r, pág. 235).

58 Se sospecha la influencia de arquitecturas y tratados arquitectónicos orientales en MARCONI, P.: "Filarete e la città sul fiume Indo. Temi vitruviani e temi orientali a confronto", en MARCONI, P. Et. al. (eds.): La città come forma simbolica. Studi sulla teoria dell'architettura nel rinascimento. Roma, Bulzoni, 1973, pág. 59 y ss.; MURATORE, G.: "Città rinascimentale e trattatistica estremo-orientale", en Ibídem., pág. 335 y ss.; MURATORE, G.: La città rinascimentale. Tipi e modelli attraverso i trattati. Milano, Gabriele Mazzotta, 1975, pág. 99 y ss.; cfr. también QUADFLIEG, R.: Filaretes Ospedale Maggiore. Zur Rezeption islamischen Hospitalwesens in der italienischen Frührenaissance. Tésis doctoral, Universidad de Colonia 1981, pág. 148 y ss. Se asume su conocimiento en el occidente del siglo XV, sin embargo no ha sido comprobado. Ya que Filarete, por su cuenta, nunca estuvo en el oriente (una carta de recomendación de su amigo Francesco Filelfo dirigida al médico griego Giorgios Amoirukios del año 1465 expresa su voluntad de hacerlo, sin embargo parece que nunca llegó a emprender el viaje; TIGLER, P.: op. cit., pág. 5 y ss.), el contacto con las arquitecturas del cercano y lejano oriente tuvo que haberse establecido a través de relatos orales o de recopilaciones de dibujos de viajeros. El "missing link" podría ser Ciriaco d'Ancona, del que sabemos que a parte de viajar a Constantinopla y a Asia Menor, se dirigió también a Egipto. Los dibujos y las descripciones de arquitecturas desconocidas que éste trajo consigo al retornar de sus viajes, han desaparecido lamentablemente a causa del incendio que tuvo lugar en la Biblioteca de los Sforza en Pesaro en el año 1514 casi por completo, y sólo se ha podido mantener en forma fragmentaria. Ciriaco d'Ancona conocía a Francesco Filelfo y de ahí seguramente también a Filarete (es mencionado como intercesor en una carta de Filfelfo dirigida al sultán Mohammed II, en la que pide la liberación de un conocido; BODNAR, E. W.: Cyriacus of Ancona and Athens, Bruselas, Latomus, 1960, pág. 68). El hecho de que Filarete realmente conoció y utilizó el diseño de Ciriaco d'Ancona, comprueba la reproducción del Mausoleo de Hadrian en la representación del Martyrium Petri en la puerta de bronce de San Pedro en Roma, que es una reproducción exacta de un esbozo de Ciriaco; cfr. ASHMOLE, B.: "Cyriac of Ancona", Proceedings of the British Academy n 45, Oxford, 1959, págs. 25-42, sobretodo pág. 36 y ss.; cfr. p.e. STÖCKHERT, L.: Die Petrus und Paulusmartyrien auf Filaretes Bronzetür von St. Peter in Rom. Eine Vorform des Panoramas als kirchenpolitische Aussage. Frankfurt am Main, Peter Lang, 1997, pág. 70 et seq. y fig. 3 y 13; sobre Ciriaco d'Ancona también WEISS, Roberto: 
ejemplo a seguir. De todas maneras, parece que Filarete considera que los representantes más honorables de la Antigüedad hay que buscarlos antes del periodo y fuera del mundo clásico. Esto nos recuerda la misma intención de los filósofos, de buscar testimonios siempre más antiguos y por lo tanto más fehacientes para una "prisca teologia", como la encontramos, aun antes de Marsilio Ficino, en el amigo de Filarete Francesco Filelfo, que aparece en el tratado del arquitecto como el traductor del Libro Dorado y intérprete de jeroglíficos egipcios ${ }^{59}$. No es por coincidencia que la impresión heráldica del humanista milanés sea una representación del Hermes Trismegistos, del fabuloso antepasado de la alquimia, cuyo país de origen se asumía tradicionalmente Egipto60.

El relato de Filarete del encuentro de un tesoro así como del Libro Dorado, que nos transmite conocimientos antiguos y muy honorables, nos recuerda las histo-

"Ciriaco d'Ancona in Oriente", en PERTUSI, A. (ed.): Venezia e l'oriente fra tardo medioevo e rinascimento. Venecia, Sansoni, 1966, págs. 323-337; además ROVETTA, A.: "Filarete e l'umanesimo greco a Milano. Viaggi, amicizie e maestri”, Arte Lombarda n ${ }^{\circ} 66$, Milano, 1983, págs. 89-102, sobretodo pág. 99 y ss.; cfr. también QUADFLIEG, R.: op. cit., pág. 148 y ss. Probablemente los paises lejanos geográfica y cronológicamente, descritos plenos de secretos en los relatos de los viajeros, le servían como lugar de proyección de sus propias ideas. Plantearse la pregunta de la influencia de arquitecturas y tratados arquitectónicos de las culturas orientales, ya es justificable por la situación geográfica de Sforzinda junto al río Sforzindo y en el valle Inda, pie de la montaña Indo. Ya habíamos señalado en ref. 22 que el único paralelismo con una planta de Palacio cuadrada, que se deja subdividir en tres por tres cuadrados y en cuyo cuadrado central se encuentra la sede del gobernador, puede ser encontrada en la tradición china.

59 Antonio Averlino... op. cit., libro XIV, fol. 103r y ss., pág. 231 y ss.); Libro XII, 87v (ibídem., pág. 202 y ss.); y con más frecuencia (cfr. ref. 60); en la mayoría de los casos, pero no siempre, puesto en un anagrama como Iscofrance Notilento (Francesco Filelfo da Tolentino). Sobre Filelfo cfr. SHEPPARD, L. A.: "A fifteenth-century humanist: Francesco Filelfo", The Library n 16, Oxford, 1935, págs. 1-26; Francesco Filelfo nel quinto centenario della morte. Atti des XVII convegno di studi maceratesi (Tolentino Sept. 1981). Padua, Ed. Antenore, 1986; ROBIN, Diana: Filelfo in Milan. Writings 1451-1477. Princeton/Nueva York, Princeton University Press, 1991. Sobre Filarete y Filelfo GARIN, E.: “La cultura a Milano alla fine del Quattrocento", en Milano nell'età di Ludovico il Moro. Convegno internazionale Mailand 1983 (28. Febr. - 4. März 1983). Milano, Comune di Milano, Archivio Storico Civico e Biblioteca Trivulziana, 1983, pág. 25 y ss.; LANG, S.: "Sforzinda, Filarete and Filelfo", Journal of the Warburg and Courtauld Institutes $n^{\circ} 35$, Londres, 1972, pág. 396 y ss.; ONIANS, John: "Alberti and Philarete. A Study in their Sources", Journal of the Warburg and Courtauld Institutes $\mathrm{n}^{\circ} 34$, Londres, 1971, pág. 106 y ss.; ROVETTA, A.: op. cit., págs. 98 y ss.

60 FIRPO, L. (ed.): Francesco Filelfo educatore e il "Codice Sforza" della Biblioteca Reale di Torino. Turín, Unione tipografica-editrice, 1967, pág. 75 y ss. Filarete pone las siguientes palabras en honor al Renacimiento en la boca del noble que había venido a visitar al Duque y que puede ser identificado como el Duque de Mantua Ludovico Gonzaga: "Señor, me parece que estoy viendo aquellos dignos edificios que había en Roma antiguamente, y los que se lee que había en Egipto. Me parece renacer cuando veo estos tan dignos edificios." (Antonio Averlino... op. cit., libro XIII, fol. 100r, pág. 231). Filelfo ya había actutado una vez como traductor; Filarete describe un teatro que había visto en Roma: "Había además en el medio un lugar en el que creo que estaban los que tenían que juzgar, y en el centro un obelisco, es decir, una aguja, que estaba esculpida toda ella con letras egipcias como ya se usaban antiguamente. - Vamos, dime qué dicen esas letras. - No os lo sé decir, porque no se pueden interpretar. Son todas letras a modo de figuras (...) hasta el punto de que son poquísimos quienes las pueden interpretar. A decir verdad, el poeta Francesco Filelfo me dijo que cada uno de aquellos animales significaba una cosa por sí mismo; la anguila significa la envidia y así cada cual tiene su significado..." (Antonio Averlino... op. cit., libro XII, fol. 87v, pág. 202 y ss.). Desde Cicero (De natura deorum III,2), Hermes valía como el autor de estos escritos; según Ficino, éste se había dirigido a Egipto, después de la ejecución de Argos, donde le transmitió al pueblo las leyes y las letras; cfr. YATES, F.: Giordano Bruno and the Hermetic Tradition. Londres, Routledge, 2002, pág. 182 y ss. Las instalaciones pictóricas del antiguo Palacio Real descritas en el Libro Dorado (es decir de aquél Palacio de 
rias provenientes de la literatura árabe, conocidas desde el siglo diez, sobre el descubrimiento de la Tabula Smaragdina u otros textos parecidos alquimistas atribuídos a Hermes. Los relatos más antiguos nos cuentan el descubrimiento de libros hermesianos en pirámides y en cámaras funerarias egiptas. Versiones más tardías tratan de hacer plausible la llegada de estos libros a otros países y su descubrimiento allí. Un ejemplo para la segunda tipología de relatos es "El Libro del Tesoro de Alejandro" perteneciente posiblemente al siglo $\mathrm{XI}$, cuya história de descubrimiento desarrollada en varios planos, presenta tantos paralelismos con el relato de Filarete que sólo se puede asumir de ello un origen directa61.

El príncipe Al-Mu'tasim después de la conquista de Amorium se había enterado de que ahí se encontraba un convento que estaba en posesión de diversas revelaciones y reliquias de los profetas. El envía a su arquitecto y a un astrólogo para que ellos inspeccionen los edificios y busquen cuartos escondidos, pero no encuentran nada. Cuando Al-Mu'tasim ya quiere ponerle fin a la búsqueda, se le aparece en sueños el legendario Al-Mamum, el primero en abrir pirámides, con las siguientes palabras: "Oh, hermano, ocúpate de la demolición de aquél muro, porque ahí se encuentra el tesoro del Du'lquarnain y la ciencia de Aristóteles y del gran Hermes! Yo te felicito, hermano mío, por toda la honra, victoria, ganancia y tan espléndida posesión, que serán las tuyas" 62 . Al día siguiente el príncipe le ordena a su arquitecto demoler lo más rápido posible, la muralla de la ciudad. Finalmente, encuentran en los fundamentos excavados, un cajón de cobre, dentro del cual se encuentra otro cajón de oro con una inscripción, y en él se encuentra un libro dorado con una inscripción en letras griegas y romeas. El príncipe hace venir a un traductor que traduce las

la ciudad porteña construído por Filarete para los Sforza), está llena de ilustraciones egipcias: (Antonio Averlino... op. cit., libro XIV, fol. 105v-107r, pág. 237 y ss.): "Estaba todo pintado con dignas historias antiguas y modernas, hechas por excelentes maestros, que representaban entre otras cosas el origen y principio de los reyes de Egipto y otras historias antiquísimas, come la de Ciro. (...) Y también cómo conquistó Semíramis el reino, y muchas de sus historias (...) Y había otras historias dignísimas de aquellos reyes y sus hazañas, como aquellas pirámides que son enormes y eternas. Estaba también la gran Tebas de Egipto, que tenía cien puertas, y finalmente todas las cosas dignas de aquellas regiones. En este palacio nuestro se representaron aún muchas cosas antiguas dignas...". Cfr. la casa del arquitecto denominada Casa Areti (Antonio Averlino... op. cit., libro XVIII, fol. 150r - libro XIX, fol. 157r, págs. 312-324; aquí libro XIX, 151v Ibídem., pág. 317): sus paredes estarán previstas de representaciones de los inspiradores del arte de la arquitectura, así como de otros artes, junto a su obra preliminar y en orden cronológico; los creadores del Laberinto de Egipto Menedotus y Velnarón son los arquitectos que se nombran en primer lugar y por lo tanto, también los primeros artistas. Cfr. HERODOT: Historiarum libri II,148; Diodorus Siculus, Bibliotheca historica I,61; Strabo, Geographica XVII,1; y sobretodo PLINIUS: Naturalis historiae XXXVI,19,84 y ss., que menciona el laberinto egipcio como el primero construído por un ser humano, en cuyo centro se había encontrado, "según la visión general", un templo dedicado al dios Sol; pero en ninguna de las fuentes se nombran los arquitectos que Filarete menciona como los responsables de la construcción. Acerca del laberinto egipcio cfr. sobretodo LLOYD, A. B.: "The Egyptian Labyrinth", The Jounal of Egyptian Archaeology n 56, Londres, 1970, págs. 81-100; cfr. KERN, H.: op. cit., pág. 69 y ss. En este contexto vale recordar a Platón que en sus obras Timeo $(3,22-23)$ y Critias $(6,113)$ le atribuye a los curas egipcios el mérito de haber mantenido en secreto el conocimiento de una comunidad citadina ideal como fue la de Atlántida.

61 Sobre el "Libro del Tesoro de Alejandro" cfr. RUSKA, J.: op. cit., pág. 64 y ss.

62 Ibídem., pág. 68. 


Q: artículos Berthold Hub

inscripciones de aquél Libro Dorado. La inscripción en el cajón exterior habla del rey Alejandro, acerca del por qué, del cómo y bajo qué constelación planetaria él había ordenado enterrar el tesoro, para que sólo pueda ser encontrado por aquél que sea digno de él, que sea tanto filósofo como rey y que vaya a cuidar del tesoro con la misma cautela que él y que lo proteja de personas no dignas de poseerlo. En un prediscurso que Aristóteles le dedica a Alejandro, el origen del tesoro es atribuída a Apollonius de Tyana y al fin a la sabiduría antediluviana de Hermes Trismegistos. A ello le siguen finalmente las doctrinas y recetas alquimistas, pronunciadas en diez partes.

Este cuento comparte los siguientes aspectos con el de Filarete: la excavación de los fundamentos de la muralla de una planta antigua llevada a cabo por un arquitecto encargado por un príncipe; durante la excavación se encuentra un tesoro de un rey antiguo; el tesoro se encuentra en una caja y dentro de la cual se encuentra otra caja, en la que está un Libro Dorado, que tiene una inscripción en letras griegas; tanto la inscripción como el libro tienen que ser traducidos por un traductor, que tiene que ser traído especialmente para llevar a cabo dicha tarea; el rey de Filarete, también está a la espera de uno digno de encontrar el tesoro, y da orden a sus sirvientes de esconder el tesoro para que sólo lo puedan encontrar aquellos que sean dignos de él63. Finalmente, el libro de Filarete también contiene secretos alquimistas.

Las cajas encontradas en los trabajos de fundamentación de la muralla de la ciudad porteña contienen aparte de diferentes objetos, también dos vasos con un polvo misterioso ${ }^{64}$. El duque que ha sido llamado para abrir las cajas, y su hijo, piensan a primera vista, que el contenido de la caja sólo es ceniza de difuntos y la quieren desechar, sin embargo, el sabio arquitecto los detiene y sugiere esperar un poco hasta que tengan la traducción del libro. Entonces, Francesco Sforza retorna a su Corte con el libro y ordena que no se continuará con los trabajos hasta que el contenido del Libro Dorado no esté traducido. Pocos días después, le llega al príncipe que se había quedado en el lugar de los trabajos de excavación la siguiente nota de su padre:

"Hijo carísimo. Te digo a ti, y tú debes transmitir a nuestro arquitecto, que estéis contentos y tratéis de hacer cosas dignas, porque hemos hecho interpretar las letras que están escritas en el libro de oro y todas las demás. Hemos oido su tenor, y entre otras cosas dicen, que el polvo que nosotros queríamos tirar es un polvo mediante el cuál, se gaste el dinero que se gaste, no faltará, porque uno de ellos pertenece al Sol y otro a la Luna, la cual pro-

63 Antonio Averlino... op. cit., libro XIV, fol. 103r, pág. 234: "Yo, el Rey Zogalia - que en nuestro idioma vulgar quiere decir sabio y rico -, como perito en muchas ciencias, dejo este tesoro en custodia a ti Folonón y a ti Orbiati, que conquistará por virtud un gran dominio; y como será magnánimo, cuando haya pacificado su estado, hará construir cosas grandes."; la observación de una constelación planetaria propicia al depositar el libro no se menciona en el relato del rey Zogaglia del Libro Dorado, sin embargo lo podemos encontrar en el relato de Filarete sobre el depósito de su propio libro de bronce al fundar la ciudad Sforzinda, que se basa y se explica a través del Libro Dorado cuando Zogaglia funda la ciudad Antigua.

64 Antonio Averlino... op. cit., libro XIV, fol. 101v, pág. 232. 
duce gran multiplicación en lo que atañe al dios que cortó la cabeza a Argos, que tenía cien ojos. $Y$ hemos encontrado el modo de hacerlo, así que alegraos y haced cosas dignas y grandes y perpetuas sin reparar en gastos...65".

El "dios que cortó la cabeza a Argos" es Mercurio, otro símbolo central en la alquimia. Y puesto que el contenido de un vaso era relacionado con el sol y el del otro relacionado con la luna, los polvos misteriosos pueden ser identificados claramente como el azufre y el mercurio de los alquimistas, los dos principios generadoras de la materia en general y las dos componentes de la Piedra Filosofal en particular. "Su padre es el sol, su madre la luna" dice en la Tabula Smaragdina de Hermes ${ }^{66}$.

También la idea de que los metales estan compuestos de dos principios elementales, se encuentra ya en Aristóteles, que hablaba de dos emanaciones en forma de humo y de vapor que la tierra expulsa, una de las cuales era caliente y seca, la otra fría y húmeda; y en base de ellas se forman los metales y minerales 67 . Luego los Estoicos reunieron los cuatro elementos en dos grupos: uno compuesto por tierra y agua era calificado como passivo y relacionado con la materia, mientras que el otro grupo, fuego y aire, era calificado como activo y relacionado con el pneuma o logos. En la Edad Media árabe estos principios por primera vez han sido relacionados con el azufre y el mercurio68. Es decir que también en esta doctrina los elementos y cualidades aritstotélicos siguen siendo la base de principios y la reducción a la materia prima, su descomposición y reconstrucción sigue siendo la estructura base para la obra de los alquimistas. El azufre se basa en los elementos fuego y aire y tiene como propiedades el calor y la sequedad, mientras que el mercurio está compuesto de agua y tierra y el frío y la humedad, los que están contrapuestas al fuego y el aire y al calor y la sequedad 69 . Azufre es el principio activo, masculino, simbolizado por el sol, mientras que mercurio es el principio receptivo,

65 Antonio Averlino... op. cit., libro XIV, fol. 102r, pág. 233

66 RUSKA, J.: op. cit., pág. 2 (frase 4: "Pater eius est Sol, mater eius Luna..."; frase 5: "Pater omnis thelesmi totius mundi est hic."). Cfr. HORTULANUS: op. cit., pág. 16 y ss.

67 Meteorologica II,6 378c.

68 Avicenna (De congelatione et conglutinatione lapidum), y el Corpus Gabirianum, escrituras que sólo se conocen por su traducción en latín, pero que se atribuyen a un árabe, cuyo nombre en latín se transformó en Gerber (la Summa perfectionis, que también se le atribuye, fue posiblemente redactada recién en el siglo XIII por un latino); casi todas las autoridades del siglo XIII, XIV y XV lo retoman con algunas modificaciones, como p.e. Albertus Magnus (De Mineralibus), Roger Bacon (Opus minus), Petrus Bonus (también Petrus Lombardus o Ferrarensis, Pretiosa margarita), la mayoría de los textos atribuídos a Raymondus Lullus (Testamentum) y a John Dastin, el texto atribuído a Arnaldo da Villanova Rosarius Philosophorum, y muchos otros más; un buen resumen general nos da THORNDIKE, L. : op. cit., vol. 3; cfr. CAMILLI, G. : "II Rosarius Philosophorum attribuito a Arnaldo da Villanova nella tradizione alchemica del Trecento", en Actes de la I trobada internacional d'estudis sobre Arnau de Vilanova. PERARNAU, J. (ed.) : Barcelona, Institut d'estudis catalans, 1995, vol. 2, págs. 175-208. La teoría dual del Mercurio/Azufre fue sostenida por el texto de la Tabula Smaragdina (y de sus comentaristas), que para todos los anteriormente enunciados era la expresión de la sabiduría de Hermes, el antepasado místico de la Alquimia. En la cuarta frase se nombran al Sol y a la Luna como los padres de la Piedra Filosofal; cfr. arriba ref. 66. 


2: artículos Berthold Hub

femenino, simbolizado por la luna. Se asumía que todos los metales igual que toda la materia están compuestos variando sus proporciones de composición de azufre y mercurio. Si el azufre y el mercurio eran combinados en el equilibrio perfecto de los cuatro elementos y de las cuatro cualidades, se creía que el resultado tenía que ser el metal perfecto, que es el oro. Sin embargo esta reunificación de principios contrarios no puede ser llevada a cabo, sin la presencia de un tercer principio que actúe como mediador entre los dos. Este medio de transformación y conjunción se llamaba igualmente "Mercurio", o "Mercurius Philosophorum", para diferenciarlo del "primer mercurio" o "mercurio común". Algunas veces este término significa agente universal de transformación, pero a veces en cambio se refiere al resultado de esta tansformación. Cuando el azufre masculino es combinado con el mercurio femenino (primer mercurio), resulta una tercera entidad nueva y perfecta. Se dice que nace como un hijo, de la unión de los arquetipos opuestos, Sol y Luna, en la "boda química".

Por lo tanto el Mercurius Philosophorum es idéntico a la Piedra Filosofal y a la quintaesencia y lo dicho ahí mantiene su validez. La alquimia no sólo actúa a un nivel físico, sino también a nivel metafísico. Mercurio no sólo es el patrón de los comerciantes y los hombres de negocios con los cuales él comparte raices etimológicas, sino también mensajero divino y mediador entre la esfera celestial y la terrestre, de lo cual se dice en la Tabula Samaragdina: "Se eleva de la tierra al cielo y luego vuelve a bajar a la tierra y absorbe la fuerza de lo que existe arriba y abajo"70. Es hermafrodita entre los planetas "masculinos" (Sol, Marte, Júpiter y Urano) y los planetas "femeninos" (Luna, Venus, Saturno y Neptuno). Es el que todo abarca y donde quedan eliminadas todas las oposiciones. Para muchos alquimistas Mercurio era el generador y multiplicador de riquezas. Para otros, Mercurio sanaba el estado post lapseriano del hombre y reestablecía la original creación divina armoniosa y perfecta.

El hecho de que Mercurio sea el equivalente latino para el Hermes griego, junto a la referencia clara al modelo de "El Libro del Tesoro de Alejandro", el que trata de una recopilación de textos alquimistas atribuídos a Hermes, tal vez nos permite reconocer en el Libro Dorado de Filarete una insinuación a una recopilación parecida de textos alquimistas atribuídos a Hermes Trismegistos, la que entonces estaba en posesión del dueño de obra, Francesco Sforza, según el inventario de 1459 de su biblioteca, y que podría haber influido de manera intensa la Sforzinda oculta, la cual hemos intentado aclarar más con este ensayo ${ }^{71}$.

69 Esta unión y contrariedad de los elementos corresponde además a las decoraciones del suelo y a las de la bóveda del pórtico del patio inferior al lado del Palacio asignado a la Duquesa, situado en la Piazza central de Sforzinda, anteriormente mencionadas.

70 RUSKA, J.: op. cit., pág. 2 (frase 8: "Ascendit a terra in coelum, iterumque descendit in terram et recipit vim superiorum et inferiorum.").

71 PELLEGRIN E.: op. cit., n. B. 96 (A. 144): Paris, Bibl. Nal. Lat. 6514: contiene aparte de la Tabula Smaragdina y otros textos atribuídos a Hermes, p.e. Albertus Magnus (De minaralibus), Marbodus (De lapidibus pretiosis), los escritos del (pseudo-) Gerber, de Razes, etc., así como la Turba Philosophorum; cfr. BIDEZ, J. et al. (ed.): Catalogue des manuscrits alchimiques latins. Bruselas, V.A.I., 1939, vol. 1, págs. 18-36 y 294-309. 